\title{
SPEAR: a proteomics approach for simultaneous protein expression and redox analysis
}

Shani Doron ${ }^{1 *}$, Nardy Lampl $^{1 *}$, Alon Savidor ${ }^{2 *}$, Corine Katina ${ }^{2}$, Alexandra Gabashvili $^{2}$, Yishai Levin ${ }^{2,3}$ and Shilo Rosenwasser ${ }^{1,3}$

\section{Affiliations:}

${ }^{1}$ The Robert H. Smith Institute of Plant Sciences and Genetics in Agriculture, The Hebrew University of Jerusalem, Rehovot 7610000, Israel

${ }^{2}$ de Botton Institute for Protein Profiling, The Nancy and Stephen Grand Israel National Center for Personalized Medicine, Weizmann Institute of Science, Rehovot, Israel

*These authors contributed equally to this work

${ }^{3}$ Corresponding authors: yishai.levin@weizmann.ac.il and shilo.rosenwaser@mail.huji.ac.il

Keywords: redox regulation; redox proteomics; N-ethylmaleimide; massspectrometry; chloroplasts; cysteine; plants 


\begin{abstract}
Oxidation and reduction of protein cysteinyl thiols serve as molecular switches, which is considered the most central mechanism for redox regulation of biological processes, altering protein structure, biochemical activity, subcellular localization, and binding affinity. Redox proteomics allows for the global identification of redoxmodified cysteine (Cys) sites and quantification of their oxidation/reduction responses, serving as a hypothesis-generating platform to stimulate redox biology mechanistic research. Here, we developed Simultaneous Protein Expression and Redox (SPEAR) analysis, a new redox-proteomics approach based on differential labeling of oxidized and reduced cysteines with light and heavy isotopic forms of commercially available isotopically-labeled N-ethylmaleimide (NEM). The presented method does not require enrichment for labeled peptides, thus enabling simultaneous quantification of Cys oxidation state and protein abundance. Using SPEAR, we were able to quantify the invivo oxidation state of thousands of cysteines across the Arabidopsis proteome under steady-state and oxidative stress conditions. Functional assignment of the identified redox-sensitive proteins demonstrated the widespread effect of oxidative conditions on various cellular functions and highlighted the enrichment of chloroplast-targeted proteins. SPEAR provides a simple, straightforward, and cost-effective means of studying redox proteome dynamics. The presented data provide a global quantitative view of cysteine oxidation of well-known redox-regulated active sites and many novel redox-sensitive sites whose role in plant acclimation to stress conditions remains to be further explored.
\end{abstract}




\section{Introduction}

As sessile organisms that grow under dynamic environmental conditions, plants must constantly sense, respond, and adapt to fluctuations in their environment. An increase in reactive oxygen species (ROS) production, emanating from oxygen-based metabolic pathways, such as photosynthesis, photorespiration and oxidative phosphorylation, has been shown to play a signaling role in plant adaption to stress conditions (Foyer and Noctor, 2005; Gadjev et al., 2006; Halliwell, 2006; Suzuki et al., 2012). Oxidative stress is a unique physiological state characterized by modulation of gene expression patterns (Gadjev et al., 2006; Rosenwasser et al., 2013; Willems et al., 2016) and metabolic activities involving ROS as a secondary messenger within complex signaling networks (Laloi et al., 2004; Halliwell, 2006). Specifically, hydrogen peroxide $\left(\mathrm{H}_{2} \mathrm{O}_{2}\right)$, one of the most studied ROS, acts as an essential messenger molecule mediating diverse cellular processes. $\mathrm{H}_{2} \mathrm{O}_{2}$ or redox changes can be sensed by monitoring the reversible oxidation of cysteine (Cys) thiol (-SH) groups to sulfenic acid (-SOH) (Winterbourn and Hampton, 2008; Petrov and Van Breusegem, 2012). The highly unstable sulfenic acid can further be oxidized by ROS, forming sulfinic acid $\left(-\mathrm{SO}_{2} \mathrm{H}\right)$ and sulfonic acid $\left(-\mathrm{SO}_{3} \mathrm{H}\right)$, or react with other cysteine residues, forming disulfide bonds (-SSR) (Yang et al., 2016). Oxidation of these reactive cysteines acts as a molecular switch, which is considered the most central mechanism for redox regulation of biological processes, altering protein structure, biochemical activity, subcellular localization and binding affinity (Waszczak et al., 2015). For instance, thiolbased signal transduction, which was first described as a regulator of chloroplast stroma activities during light-driven electron flux (Buchanan and Balmer, 2005), was found to be particularly important in photosynthetic organisms that have to rapidly respond to fluctuating light intensities and multiple environmental cues (Dietz and Pfannschmidt, 2011; Scheibe and Dietz, 2012). Thus, identifying redox-modified proteins and quantifying cysteine reactivity is critical in understanding how plants perceive and respond to transducing redox signals in changing environmental conditions.

Recent advancements in mass spectrometry (MS) technology have led to the development of various proteomics techniques to detect reversibly modified cysteines, which have enabled system-level identification of redox-sensitive proteins. Thioredoxins (Trxs) and glutaredoxins (Grxs)-regulated proteins in plants were thoroughly characterized by applying trapping chromatography using single-cysteine 
Trx or Grx mutant which forms a stable mixed disulfide bond with target proteins (Balmer et al., 2004; Rouhier et al., 2005; Yoshida et al., 2013; Buchanan, 2016). Such methods allowed the identification of numerous redox-regulated proteins and demonstrated the prevalence of redox regulation across plant metabolic pathways and molecular processes. However, a more in-depth understanding of redox dynamics requires in-vivo quantification of the redox-modified site under diverse physiological conditions, which is not enabled by monothiol mutant-based trapping approaches.

Several gel-free, site-specific, and quantitative redox approaches have been developed to identify redox-sensitive cysteine sites (Lennicke et al., 2016; Yu et al., 2020). For example, the OxiTRAQ uses the biotin-switch method to differentially label thiol groups, which can then be identified and quantified using the iTRAQ method, as applied to suspended Arabidopsis cells treated with $\mathrm{H}_{2} \mathrm{O}_{2}$ (Liu et al., 2014). Relative quantitation of reversibly oxidized cysteine-containing peptides using the Cys tandem mass tag (cysTMT) was demonstrated in tomato plants in response to Pseudomonas syringae (Balmant et al., 2015). When irreversible labeling of Cys using iodoTMT reagents is combined with iTRAQ tags, both changes in protein levels can be quantified and redox-modified Cys in proteins identified (Parker et al., 2015). This hybrid approach, named iodoTMTRAQ, was recently employed to analyze changes in protein redox modifications in suspended Arabidopsis thaliana cells in response to bicarbonate (Yin et al., 2017). As most redox proteomics approaches use reducing agents such as DTT or TCEP to indiscriminately reduce all modified cysteines, the exact chemical Cys modification cannot be distinguished. Thus, identifying a precise modification requires either the use of a specific reducing reagent or direct thiol labeling of a specific Cys modification. For example, using a set of S-sulfenylation-specific probes enabled highly comprehensive characterization of S-sulfenylated cysteines in Arabidopsis cells (Waszczak et al., 2014; Akter et al., 2015; De Smet et al., 2019; Huang et al., 2019). Most quantitative redox proteomics analyses detect either the reduced or the oxidized state of a given thiol, presenting fold-change values between control and treatment by comparing the incorporation of an alkylating probe in different samples (Mock and Dietz, 2016). In contrast, redox proteomics methods that are based on differential labeling of reduced and oxidized thiols with isotopically light and heavy forms of thiolalkylating agents, such as the OxiCAT or iodoacetyl tandem mass tag (iodoTMT), enable precise measurement of the percent of cysteine oxidation (Leichert et al., 2008; Brandes et al., 2011; Nietzel et al., 2020). The later value is of high importance to 
identify Cys that their redox modulation has significant physiological effects. Recently, OxiCAT provided a comprehensive view on the diatom Phaeodactylum tricornutum redoxome and insights into its evolution (Rosenwasser et al., 2014; Woehle et al., 2017). Notably, as OxiCAT and iodoTMT requires the enrichment of cysteine-labeled peptides, data regarding protein expression is lost during sample processing and cannot be analyzed simultaneously with cysteine redox changes. Also, the intensive manual work involved in peptide purification by affinity chromatography and the cost of chemicals required for Cys trapping limits the number of samples that can be analyzed in a single experiment.

Two recently developed redox proteomics approaches allow determining the percent of oxidation of identified Cys-containing peptides and relative quantification of protein abundance in the same experiments (Anjo et al., 2019; Xiao et al., 2020). Deep coverage and quantification of the tissue-specific mouse Cys proteome were achieved using IAM-based cysteine-reactive phosphate tags coupled with TMT isobaric reagents (Xiao et al., 2020). Using commonly available alkylating reagents, oxSWATH combines label-free protein expression profiling with differential alkylation to quantify relative redox changes on a global scale (Anjo et al., 2019). These protocols are based on splitting the original sample into two or three identical sub-samples that undergo complementary differential alkylation labeling procedures and have not been adopted to plant tissue.

Here, we developed a new redox-proteomics approach that is based on differential labeling of oxidized and reduced cysteines with commercially available light (d0) and heavy (d5) isotopic forms of the common thiol-alkylating reagent $\mathrm{N}$ ethylmaleimide (NEM). By mixing samples in which reduced cysteines were labeled with $\mathrm{d} 0$-NEM or $\mathrm{d} 5-\mathrm{NEM}$, peptide fractionation using high $\mathrm{pH}$ reversed-phase chromatography, online nanoflow liquid chromatography (nanoAcquity), high mass accuracy, tandem mass spectrometry (Q-Exactive HF), and a next-generation search engine, we were able to quantify the in-vivo oxidation state of thousands of cysteines across the Arabidopsis proteome under steady-state and oxidative stress conditions. The presented data provide a global quantitative view of cysteine oxidation in photosensitizing plant leaves. 


\section{Results and Discussion:}

\section{$\underline{\text { Intracellular response to hydrogen peroxide }}$}

We aimed to detect and quantify reactive thiols on a system level, under steady-state conditions and following exposure to physiologically relevant hydrogen peroxide $\left(\mathrm{H}_{2} \mathrm{O}_{2}\right)$ concentrations. To examine the intracellular response to $\mathrm{H}_{2} \mathrm{O}_{2}$, we measured the oxidation state of chloroplast 2-Cys peroxiredoxin (2-Cys-Prx), as previously demonstrated for isolated chloroplasts (Muthuramalingam et al., 2013). 2-Cys-Prx can serve as a sensor for intracellular oxidation state, reflected in its oligomeric form. The oxidation state of 2-Cys-Prx was determined by measuring the relative amounts of the dimeric (oxidative) versus monomeric (reduced or hyperoxidized) forms on nonreducing SDS-PAGE using a 2-Cys-Prx-specific antibody. As shown in Fig. 1a\&b, a major increase in the relative abundance of the 2-Cys-Prx oxidized states (out of total 2-Cys-Prx) from $56 \%$ to $88 \%$ and $80 \%$ was achieved following the application of $10 \mathrm{mM}$ and $50 \mathrm{mM} \mathrm{H}_{2} \mathrm{O}_{2}$, respectively. The observed monomeric form may also represent the hyperoxidized 2-Cys-Prx, the higher oxidation state of 2-Cys-Prx catalytic site sulfonic $\left(-\mathrm{SO}_{3}{ }^{-}\right)$derivative. A high level of hyperoxidized 2-Cys-Prx may be an indication of deleterious $\mathrm{H}_{2} \mathrm{O}_{2}$ concentrations and activities aimed at protecting cells against oxidative damage by maintaining the reduced state of thioredoxins and increasing signaling via 2-Cys-Prx. (Veal et al., 2018). Thus, an accumulation of the hyperoxidized 2-Cys-Prx was measured using an antibody raised specifically against this irreversible $\left(-\mathrm{SO}_{3}{ }^{-}\right)$hyperoxidized state (Fig. 1a low panel \&b). Only a minor and moderate increase in hyperoxidation 2-Cys-Prx was observed following treatment with $10 \mathrm{mM}$ and $50 \mathrm{mMH}_{2} \mathrm{O}_{2}$, respectively, while a significant increase was detected following treatment with $100 \mathrm{mM} \mathrm{H}_{2} \mathrm{O}_{2}$.

To further check whether the exogenously applied peroxide significantly affects the reactive thiols in other subcellular localizations, we examined the oxidation state of the redox-specific in-vivo sensor, roGFP2, targeted to specific subcellular compartments in response to exogenous application of $\mathrm{H}_{2} \mathrm{O}_{2}$ (Fig. 1c). Whole-plant fluorescence imaging analysis showed partial oxidation of the probe in the chloroplast, mitochondria, peroxisome and cytoplasm following treatment with $10 \mathrm{mM}$ and $50 \mathrm{mM} \mathrm{H}_{2} \mathrm{O}_{2}$, while full oxidation was only achieved following treatment with $500 \mathrm{mM} \mathrm{H}_{2} \mathrm{O}_{2}$ (Fig. 1c). Thus, concentrations of $10 \mathrm{mM}$ and $50 \mathrm{mM} \mathrm{H}_{2} \mathrm{O}_{2}$ were further used to represent physiological $\mathrm{H}_{2} \mathrm{O}_{2}$ concentrations that affect proteins in diverse subcellular localizations. 

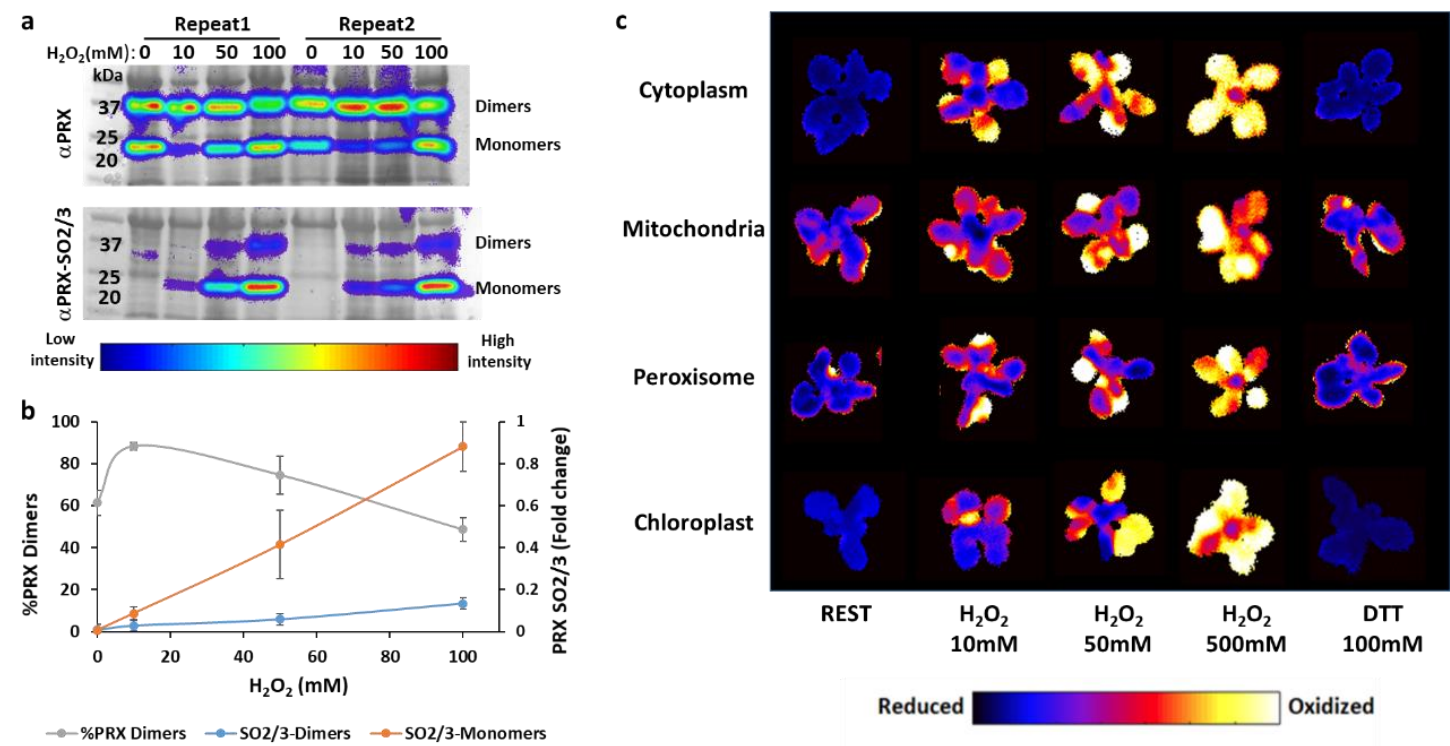

Figure 1. Dose-dependent response of chloroplastic 2-Cys peroxiredoxin and organelle-targeted roGFP2 to increasing concentrations of $\mathbf{H}_{2} \mathrm{O}_{2}$. (a) Immunoblot showing the oxidized state of 2-Cys peroxiredoxin (upper panel) and the hyperoxidized forms of peroxiredoxin $-\mathrm{SO}_{3}$ (lower panel) in Arabidopsis plants after exposure to increasing concentrations of $\mathrm{H}_{2} \mathrm{O}_{2}(10-100 \mathrm{mM})$ for $20 \mathrm{~min}$. Total protein was extracted using TCA and free thiols were blocked with N-ethylmaleimide (NEM). (b) Quantification of the relative abundance of oxidized 2-Cys peroxiredoxin (dimer) and hyperoxidized peroxiredoxin forms presented in a. The relative abundance of the hyperoxidized form was quantified as a percentage of the intensity measured following treatment with $0-100 \mathrm{mM}$ $\mathrm{H}_{2} \mathrm{O}_{2}$. Values represent the mean $\pm \mathrm{SD}$ of two biological replicates. (c) Whole-plant ratiometric imaging of Arabidopsis plants expressing roGFP2 in the cytoplasm, mitochondria, peroxisome, or chloroplasts, and subjected to $\mathrm{H}_{2} \mathrm{O}_{2}$ and DTT treatments.

\section{Global quantification of Cys oxidation}

To comprehensively characterize the cellular responses of Arabidopsis leaves to the early phase of oxidative stress, we aimed to detect and quantify reactive thiols on a system level, under steady-state conditions and following exposure to physiological hydrogen peroxide $\left(\mathrm{H}_{2} \mathrm{O}_{2}\right)$ concentrations. Our approach for global quantification of the Cys redox state, termed SPEAR (simultaneous protein expression and redox analysis), is based on rapid acidification of plant extracts with trichloroacetic acid (TCA) to preserve redox status of thiol groups, followed by differential labeling with isotopically light (d0) (reduced cysteines), and heavy (d5) (oxidized cysteines) forms of NEM, as demonstrated by (McDonagh et al., 2014, Fig. 2a). The identity and abundance of the reduced and the oxidized forms of specific peptides can be determined based on $5 \mathrm{Da}$ mass difference between the light and heavy peptides. Trypsin-digested peptides were directly analyzed by LC-MS/MS proteomics without enrichment of cysteine-containing peptides, thus also enabling protein level quantification, since the data includes nonmodified peptides of these proteins. 
To expand the total number of identified peptides, sample fractionation using high $\mathrm{pH}$ reversed-phase chromatography was carried out, followed by online nanoflow liquid chromatography (nanoAcquity) and high-resolution high mass accuracy, tandem mass spectrometry (Q-Exactive HF). The recently developed MetaMorpheus (MM), a nextgeneration search engine (Solntsev et al., 2018), was employed to identify and quantify light and heavy NEM-labeled peptides. Quantification was achieved by comparing the area under the curve of the light and heavy-labeled peptides at the intact peptide level (MS1). Importantly, unlike differential labeling with carbon isotopes (as used in OxiCAT), in which the light and heavy forms of the same peptide elute at the same time, the difference in hydrophobicity between hydrogen and deuterium of the d0-NEM and d5-NEM peptides results in unequal retention times (RT) (Fig. S1). For this reason, the RT data cannot be used in matching light and heavy peptides, and identification by MS/MS of each form is required.

To test the capabilities of this relatively simple and straightforward workflow, plants were treated with $10 \mathrm{mM}$ or $50 \mathrm{mM} \mathrm{H}_{2} \mathrm{O}_{2}$ for $20 \mathrm{~min}$, as was done in the aforementioned experiments to establish the physiological conditions, and subjected to d0-NEM and d5-NEM labeling of reduced and oxidized Cys thiols, respectively (Fig. 2a). Two biological replicates were performed $\mathrm{f}$ each treatment, resulting in six sample and a total of 36 LC-MS/MS runs. Using the G-PTM-D algorithm of MM, 3689 d0-NEM and 518 d5-NEM labeled unique peptides were identified, enabling the quantification of the degree of oxidation of 412 cysteines. In this dataset, 17 cysteines exhibited a significantly increased degree of oxidation under oxidative stress conditions and were identified as redox-sensitive (Table S1).

We recognized that the relatively small number of identified d5-NEM-labeled peptides compared with d0-NEM labeled peptides resulted from the highly reduced state of most thiol groups, hindering the ability to accurately identify, by MS/MS, the fraction of oxidized peptides due to their low abundance. To overcome this limitation, we expanded our approach by analyzing an additional set of samples in which the reduced Cys groups were labeled with d5-NEM (we referred to this as "opposite labeling"), allowing us to precisely extract their $\mathrm{m} / \mathrm{z}$ values and their specific RT. Then, by applying the MM 'match between runs' algorithm, the MS profiles derived from the opposite labeling samples served as markers to locate the corresponding peptides in the 
core samples labeled with d0-NEM and d5-NEM for the reduced and oxidized Cys states, respectively.

To examine the applicability of this approach, proteins extracted from control, $10 \mathrm{mM}$ and 50mM H2O2-treated plants were labeled with d0-NEM and d5-NEM for the reduced and oxidized Cys states, respectively. An additional set of samples was oppositely labeled, as described above. As shown in Fig. 2b, the number of d5-NEMlabeled peptides in the eight-core samples increased significantly due to their coanalysis with those having reduced Cys labeled with d5-NEM, resulting in the higher number of identified $\mathrm{d} 5 / \mathrm{d} 0$ pairs. These results demonstrated that by adding oppositely labeled "marker" samples, the number of identified Cys could significantly increase without purifying and enriching labeled peptides. In total, double labeling with both the heavy and the light NEM reagents was recorded for 5523 peptides, representing 2967 distinct proteins in the Arabidopsis proteome. This was achieved by combining protein search data of G-PTM-D and variable modification approaches provided in the MM platform, demonstrating in-depth analysis of the redox proteome without bias toward only highly abundant proteins. Most ( $96 \%)$ of the identified Cys-containing peptides were found to be NEM-labeled, pointing to the high efficiency of the labeling procedure. Interestingly, we found that NEM-labeled cysteine residues were in close proximity to a consensus motif significantly enriched with glutamic acid and aspartic acid (Fig. 2c). This motif was not detected in identified Cys-containing peptides that were not labeled with NEM (Fig. S2), suggesting that these acidic amino acids enhance cysteine reactivity to NEM. 
a
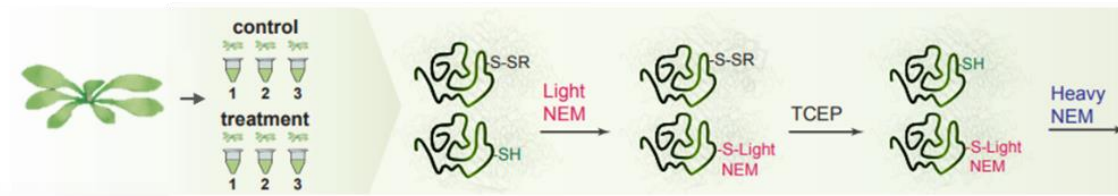
Gु? S-Heav NEM S-Light

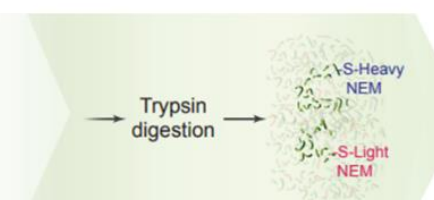

NEM

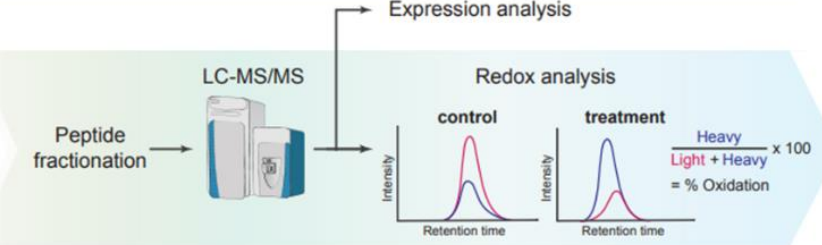

b

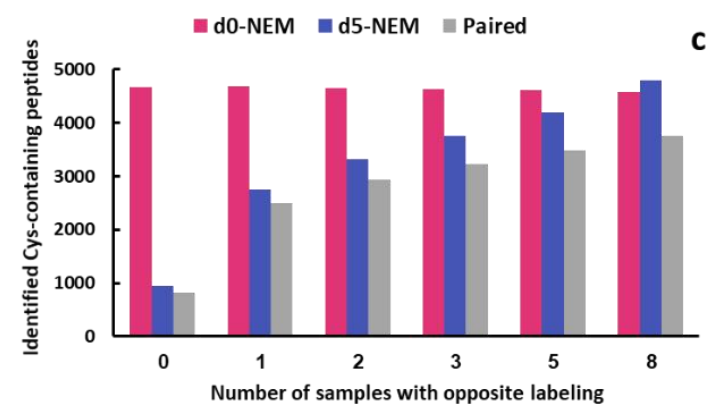

C

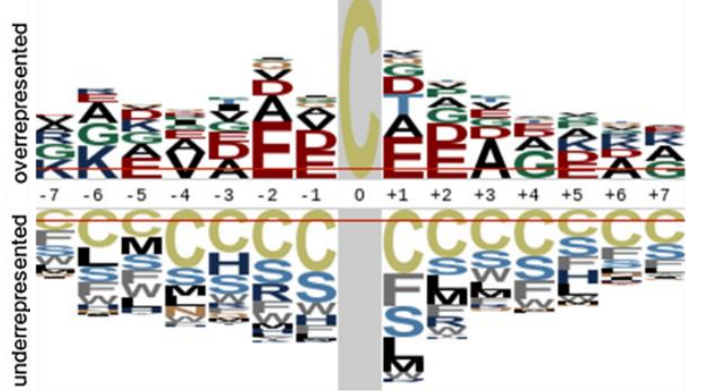

Figure 2: Simultaneous quantification of Cys oxidation state and protein expression levels using the SPEAR approach. (a) Schematic representation of the NEM-based differential alkylation method used to evaluate Cys degree of oxidation and protein abundance. S-SR and SH signify an oxidized and a reduced Cys of a represented redox sensitive protein, respectively. The abundance of the reduced and the oxidized forms of a specific peptide can be distinguished based on the $5 \mathrm{Da}$ mass difference between the light- and heavy-labeled peptides. As no enrichment and purification steps were included, data regarding protein expression was maintained and extracted using common label-free protein quantification approaches. (b) The number of identified peptide pairs (labeled with d0 and d5 NEM) was greatly enhanced by the co-analysis of peptides labeled as described in A and peptides in which reduced Cys were labeled with d5 NEM (opposite labeling). The increase in the number of identified d0-labeled, d5 labeled peptides and pairs due to the addition of samples with opposite labeling using only the G-PTM-D approach is presented. (c) The consensus motif of NEM-labeled peptides demonstrates significant enrichment of aspartic and glutamic acid near the modified Cys. The Arabidopsis thaliana proteome was used as the proteomic background population for the calculation of the probabilities. Similar analysis done for non-labeled Cys containing peptides is presented in Supp. Fig. 2.

While commonly used redox proteomics approaches are semi-quantitative and report the fold-change between specific oxidation states (reduced or oxidized) in control versus treated samples, the ability of SPEAR to measure both the exact percent of modified cysteines (i.e., site occupancy) and protein levels enables to determine whether the oxidation of specific cysteines alone (i.e. without additional transcriptional/translational regulation) is sufficient to elicit a significant physiological consequence. This valuable information regarding redox regulatory nodes is critical when redox networks are assembled for computational simulation to describe basic parameters of the thiol regulatory networks (Gerken et al., 2020). To conclude, we propose combining peptide fractionation and parallel running of samples with regular and reverse labeling to identify high numbers of labeled pairs without necessitating enrichment for labeled peptides, enabling retention of overall protein abundance data. 
bioRxiv preprint doi: https://doi.org/10.1101/2021.06.17.448798; this version posted June 17, 2021. The copyright holder for this preprint (which was not certified by peer review) is the author/funder, who has granted bioRxiv a license to display the preprint in perpetuity. It is made available under aCC-BY-NC-ND 4.0 International license.

\section{The Arabidopsis redox proteome}

The degree of oxidation was calculated for each cysteine based on the intensity of the light and heavy peptides. The median degree of oxidation of cysteines under steadystate conditions, following low $(10 \mathrm{mM})$ and high $(50 \mathrm{mM}) \mathrm{H}_{2} \mathrm{O}_{2}$ treatments, was $19.85 \%, 27.45 \%$, and $28.93 \%$, respectively, demonstrating that the majority of the Cys remained highly reduced even under oxidative stress conditions. In total, we found 577 cysteine-containing peptides, representing 525 proteins, that exhibited a significant change in their degree of oxidation $(|\Delta \mathrm{OX}|>10 \%$ and $P$-value $<0.05)$ under oxidative stress conditions (Fig. 3a\&b and Table S2). These results, which indicate the specificity of redox signaling, are consistent with earlier redox proteomics surveys, which showed that only a distinct subset of thiols undergoes stable, yet reversible, thiol modification in response to $\mathrm{H}_{2} \mathrm{O}_{2}$ (Brandes et al., 2011; Liu et al., 2014; Rosenwasser et al., 2014; Fu et al., 2017).
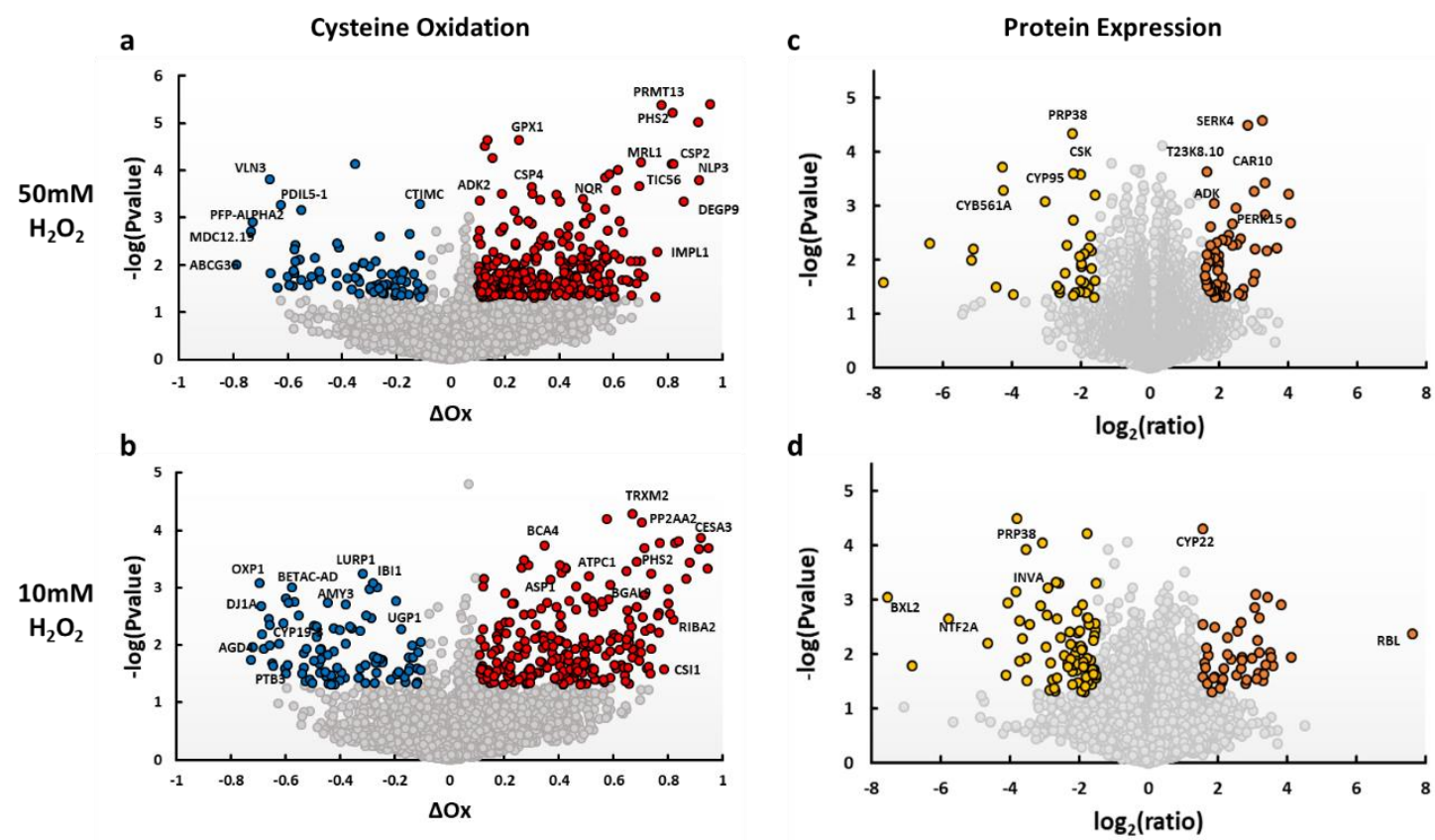

Figure 3: Simultaneous quantification of Cys oxidation state and protein expression levels under oxidative stress conditions. Whole rosettes of 3-week-old Arabidopsis plants were soaked in $10 \mathrm{mM}$ or $50 \mathrm{Mm} \mathrm{H}_{2} \mathrm{O}_{2}$ and subjected to SPEAR analysis. (a, b) Volcano plot visualization of the response of 5523 unique cysteine-containing peptides to $10 \mathrm{mM}$ (b) or $50 \mathrm{mM}$ (a) $\mathrm{H}_{2} \mathrm{O}_{2}$. Colored dots highlight Cys with a $\geq 10 \%$ change in oxidation $(\Delta \mathrm{Ox})$ and a p-value $<0.05$ in $\mathrm{H}_{2} \mathrm{O}_{2}$-treated plants compared to control. (c, d) Volcano plot visualization of the expression profile of 7493 proteins following treatment with $10 \mathrm{mM}$ (d) or $50 \mathrm{mM}(\mathbf{c}) \mathrm{H}_{2} \mathrm{O}_{2}$. Colored dots highlight proteins with an average $\geq 1.5 \log 2$-fold change in $\mathrm{H}_{2} \mathrm{O}_{2}$-treated plants compared to control and a p-value $<0.05$. 
Examination of protein abundance showed that the level of 127 and 96 proteins was altered in response to a 20 -min exposure to $10 \mathrm{mM}$ or $50 \mathrm{mM} \mathrm{H}_{2} \mathrm{O}_{2}$, respectively (| $\mathrm{Log}_{2}$ $\mathrm{FC} \mid>1.5, P$-value $<0.05$, Table S3), including upregulation of several protein kinases, such as PROLINE-RICH EXTENSIN-LIKE RECEPTOR KINASE 15 (PERK15). Interestingly, we did not find any overlap between proteins that underwent oxidization and proteins whose expression level changed under oxidative stress, demonstrating the independence of these two regulatory modes. The relatively minor alteration in protein abundance compared with the major cysteine modifications, emphasizes the role of redox regulation in the rapid modulation of protein activity.

SUBA, a tool to investigate proteins subcellular localization in Arabidopsis was then used to predict the location of the identified proteins (Hooper et al., 2017). The analysis revealed that redox-sensitive proteins were found in all cell compartments, in agreement with observed roGFP oxidation in all examined subcellular localization (Fig. 1c). It also revealed an over-representation of plastid-targeted proteins (22\% of identified proteins and $32 \%$ of redox-sensitive proteins, hypergeometric test $\mathrm{p}=$ $1.264 \mathrm{E}^{-08}$, Fig. 4a\&b). Thus, despite the high antioxidant buffer capacity of the chloroplast, its proteome is enriched in redox-sensitive proteins, highlighting the widespread role of redox regulation in chloroplast reactions. Cytosolic proteins were also overrepresented in the redox-sensitive proteins (21\% of identified proteins and $28 \%$ of redox-sensitive proteins, hypergeometric test $\mathrm{p}=4.394 \mathrm{E}-{ }^{05}$ ). Among them were 16 translation-related proteins, in agreement with the ROS sensitivity of the translation machinery recently observed in yeast cells (Topf et al., 2018). GO (Gene Ontology) and KEGG (Kyoto Encyclopedia of Genes and Genomes) assignment of redoxsensitive proteins included the enrichment of redox-related terms, such as peroxiredoxin activity (GO:0051920) and iron-sulfur cluster binding (GO:0051539), as well as the overrepresentation of various metabolic pathways, such as glycolysis (ath00010) and carbon fixation (ath00710) (Fig. 4c).

Hierarchical clustering of redox-sensitive proteins, based on the degree of oxidation, showed enrichment of several clusters with differential redox sensitivity in specific biological pathways (Fig. 4d). Of note was a cluster of proteins in which their reactive Cys underwent reduction in response to $\mathrm{H}_{2} \mathrm{O}_{2}$ treatment. These counterintuitive results, that were also reported in other redox proteomics analyses (Wang et al., 2012; Liu et al., 2014), demonstrate the transmission of reductive signals under oxidative stress conditions. For example, we detected a reduction of $\mathrm{Cys}^{218}$ of the mitochondrial NifU- 
like protein $\left(\Delta \mathrm{OX} \mathrm{X}_{\mathrm{L}}=-40 \%, \Delta \mathrm{OX}_{\mathrm{H}}=-57 \%\right)$ and $\mathrm{Cys}^{209}$ of chloroplastic phosphoglucomutase $\left(\Delta \mathrm{OX} \mathrm{X}_{\mathrm{L}}=-13 \%, \Delta \mathrm{OX} \mathrm{H}=-11 \%\right)$. In yeast, it has been suggested that hyperoxidation of 2-Cys peroxiredoxin results in preservation of reduced thioredoxin, which then reduces its targets and repairs oxidative damage, providing a rational mechanism for $\mathrm{H}_{2} \mathrm{O}_{2}$ induced reduction of thiols under oxidative stress conditions (Day et al., 2012). A reduction of $\mathrm{H}_{2} \mathrm{O}_{2}$-target proteins in response to peroxiredoxin inactivation is also suggested by the peroxiredoxin redox relay model (Calabrese et al., 2019). However, as shown in Fig. 1a\&b, our data indicated only minor hyperoxidation of chloroplastic 2-Cys peroxiredoxin. Thus, the observed reduction of specific protein groups may result from the hyperoxidation of other peroxiredoxins or that even minor levels of 2-Cys peroxiredoxin hyperoxided state are sufficient to induce Cys reduction. Alternatively, besides hyperoxidation, inhibition of metabolic activity that consumes reducing power, such as carbon fixation, may result in a diversion of reducing power to protein targets. 
bioRxiv preprint doi: https://doi.org/10.1101/2021.06.17.448798; this version posted June 17, 2021. The copyright holder for this preprint (which was not certified by peer review) is the author/funder, who has granted bioRxiv a license to display the preprint in perpetuity. It is made available under aCC-BY-NC-ND 4.0 International license.

a

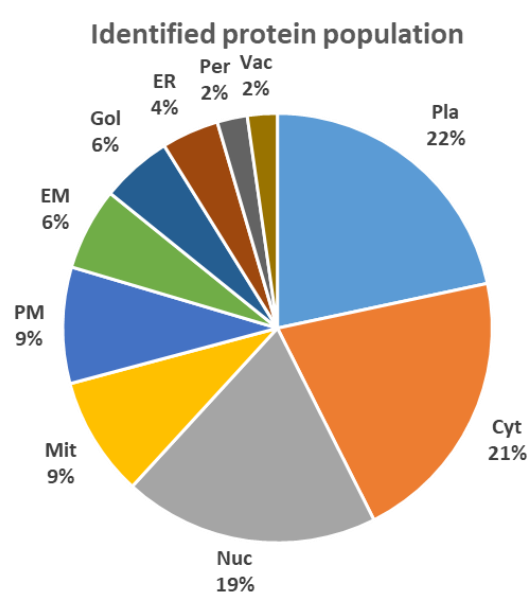

C

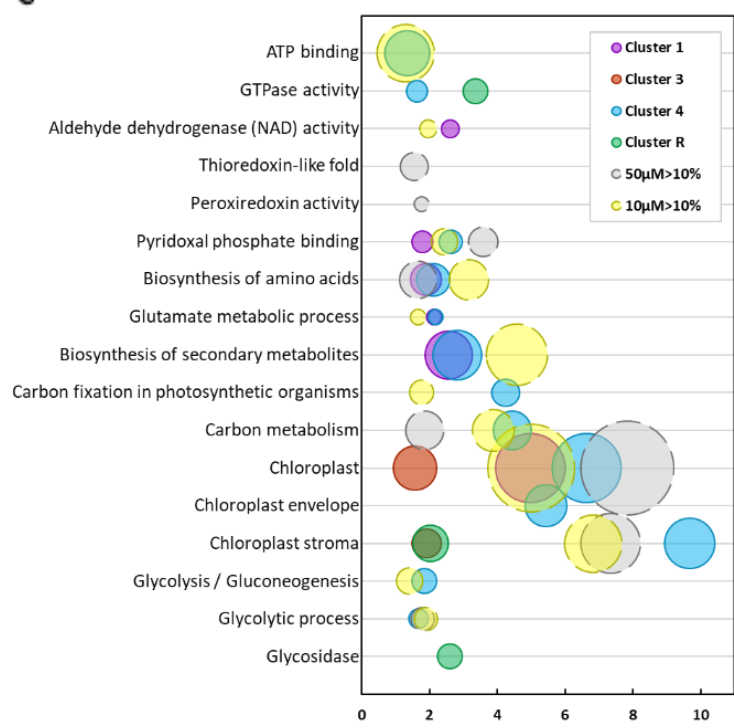

b

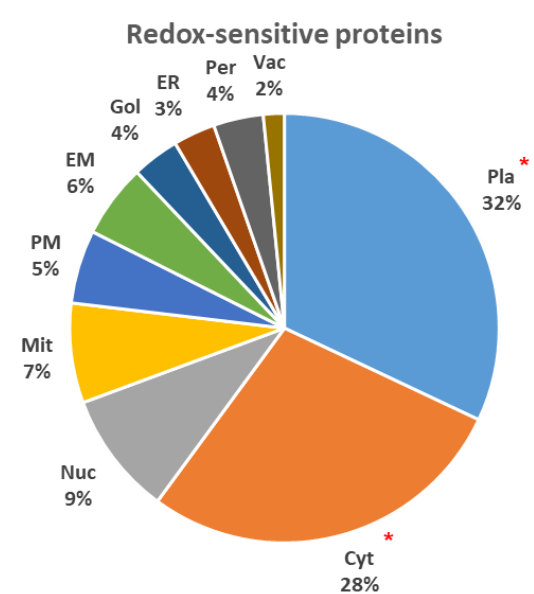

d

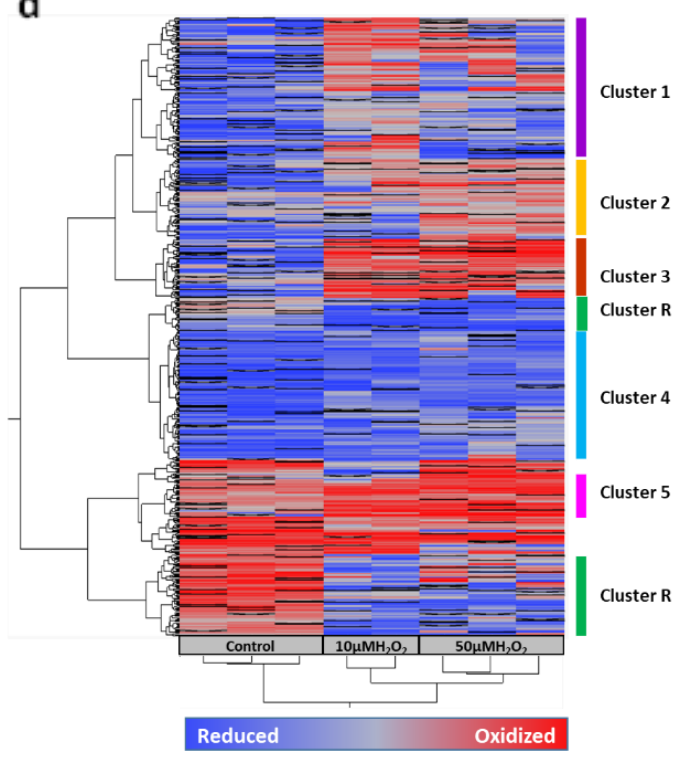

Figure 4: Distribution of redox-sensitive proteins among subcellular compartments and global Cys oxidation profiles of the Arabidopsis plant under oxidative stress conditions. (a,b) Subcellular distribution of redoxsensitive proteins were assigned using the SUBA tool (Hooper et al., 2017). The percentage of proteins in each compartment from the (a) entire identified protein population and (b) redox-sensitive proteins is depicted. Distribution of the thiol-oxidized state between steady state and exposure to 10 and $50 \mathrm{mM} \mathrm{H}_{2} \mathrm{O}_{2}$ treatment in different subcellular compartments is presented in Fig. S5. (c) Significantly enriched GO terms and KEGG pathways (hypergeometric test, $\mathrm{P}<0.05$ ) in redox-sensitive proteins (change in the oxidation of $\geq 10 \%$ and a P-value $<0.05$ ) and clusters as displayed in (d). For a full list of enriched biological pathways in each cluster, see Supplemental Data Set 2. (d) Hierarchical clustering of $577 \mathrm{Cys}$ with altered oxidation state in response to $10 \mathrm{mM}$ or $50 \mathrm{mM} \mathrm{H}_{2} \mathrm{O}_{2}$. Red, high oxidation state; blue, low oxidation state. *hypergeomtric test <0.01. Pla, plastid; Cyt, cytosol; Nuc, nucleus; Mit, mitochondrion; PM, plasma membrane; EM, extracellular matrix; Gol, golgi ; ER, endoplasmic reticulum ; Per, peroxisome; Vac, vacuole. 


\section{The functionality of redox-sensitive cysteines}

Functional annotation retrieved for all the quantified cysteines from the UniProt knowledgebase (https://www.uniprot.org/, Consortium, 2019) indicated an overrepresentation of active-site cysteines (hypergeometric test, p-value $=0.00015$, Supp. Table 2) and of redox-sensitive Cys residues involved in disulfide bridges (hypergeometric test, $\mathrm{p}$-value $=0.0268$, Supp. Table 2 ) in the redox-sensitive cysteines compared to the all quantified cysteines. Among the observed active-site cysteines were known redox-regulated sites such as glutathione-dependent dehydroascorbate reductase (DHAR) and glutathione peroxidase 1 (GPX1). Other oxidized active site Cys residues included Cys ${ }^{139}$ of ATP synthase gamma chain 1 (ATPC1), Cys ${ }^{106}$ of ferredoxindependent glutamate synthase 1 (GLU1), Cys ${ }^{156}$ of Glyceraldehyde-3-phosphate dehydrogenase $\mathrm{C}$ subunit (GAPC) and $\mathrm{Cys}^{184}$ of plastid rhodanese-like protein 11 (AtStr11). Among the redox-sensitive cysteines involved in disulfide formation were Cys ${ }^{187}$ in magnesium-chelatase subunit ChlI-2 (CHLI2), which has been shown to form a disulfide with $\mathrm{Cys}^{96}$ under oxidative conditions (Ikegami et al., 2007), $\mathrm{Cys}^{217}$ in NADPH-dependent thioredoxin reductase 3 (NTRC), which forms a disulfide with $\mathrm{Cys}^{220}$ and $\mathrm{Cys}^{157}$ of glucose-6-phosphate 1-dehydrogenase 1 (G6PDH1), which is involved in redox modulation of the oxidative pentose-phosphate pathway (Wenderoth et al., 1997).

Moreover, twelve reactive sites were found to be involved in zinc ( 9 sites) and ironsulfur ( 3 sites) cluster coordination. Oxidation of these cysteines can lead to metal release, resulting in altered protein conformation and function (D'Autréaux and Toledano, 2007). We also identified and quantified the redox sensitivity of Cys ${ }^{139}$ $\left(\Delta \mathrm{OX}_{\mathrm{H}}=38 \%\right)$, which is involved in the coordination of zinc in PSA2 - a thylakoid member of the DnaJ-like zinc finger domain protein family that affects light acclimation and chloroplast development by regulating the biogenesis of photosystem I (PSI) (Fristedt et al., 2014). Oxidation of these Cys residues under oxidative stress conditions can serve as a mechanism that slows down photosynthesis under stress conditions. $\mathrm{Cys}^{644}(\Delta \mathrm{OX} \mathrm{L}=66 \%)$ involved in the coordination of iron-sulfur cluster was found in an oxidized state in 4-hydroxy-3-methylbut-2-en-1-yl diphosphate synthase (ISPG), which is involved in the plastid non-mevalonate pathway for isoprenoid biosynthesis. As the electrons required for ISPG activity are directly provided by the electron flow from photosynthesis via ferredoxin, oxidation of these Cys residues may regulate the electron flux through this pathway. 


\section{Quantification of redox reactivity in redox sensors and regulators}

An increase in the abundance of the oxidative state of many known redox sensors and regulators was detected following exposure to hydrogen peroxide, reinforcing the validity of the redox proteomics approach and its high sensitivity in capturing in vivo states of thiol proteins (Fig. 5a). For example, the extracted ion chromatograms illustrated the redox sensitivity of the $\mathrm{Cys}^{111}\left(\Delta \mathrm{OX} \mathrm{X}_{\mathrm{H}}=16 \%\right)$ of the catalytic site of peroxiredoxin Q (PRXQ) (Fig. 5b). This protein was shown to attach to the thylakoid membrane and was suggested to play a role in protecting photosystem II against hydrogen peroxide (Lamkemeyer et al., 2006). Major oxidation was also measured in the catalytic site of peroxiredoxin-2E (PRXIIE, $\left.\mathrm{Cys}^{121}, \Delta \mathrm{OX}_{\mathrm{H}}=59 \%\right)$, which has been implicated in light acclimation (Rouhier and Jacquot, 2005) and subjected to SNitrosylation (Romero-Puertas et al., 2007). Oxidation of the resolving thiol, Cys ${ }^{241}$, of 2-Cys-Prx (BAS1, $\Delta \mathrm{OX}_{\mathrm{L}}=23 \%, \Delta \mathrm{OX}_{\mathrm{H}}=24 \%$, Fig. S3 and Supp. Table 2), was also detected, confirming the shift toward its oxidative state as observed by western blot analysis (Fig. 1a). The high reactivity of BAS1 to $10 \mathrm{mM} \mathrm{H}_{2} \mathrm{O}_{2}$ compared to the low reactivity of PRXIIE point for the coexistence of two plastids-targeted peroxiredoxin with altered reactivity toward peroxide, possibly providing a mechanism for stepwise sensing of $\mathrm{H}_{2} \mathrm{O}_{2}$ levels, as recently pointed for human peroxiredoxins (PortilloLedesma et al., 2018). We also quantified the oxidation response of the catalytic cysteines of the chloroplastic Thioredoxin M2 (TRXM2), Cys110 and Cys113 $\left(\Delta \mathrm{OXL}=67 \%, \Delta \mathrm{OX}_{\mathrm{H}}=44 \%\right)$, the catalytic cysteines, $\mathrm{Cys}^{217}$ and $\mathrm{Cys}^{220}$ involved in the thioredoxin reductase activity of NADPH-dependent thioredoxin reductase C (NTRC, $\Delta \mathrm{OX}_{\mathrm{L}}=58 \%$ ), and the catalytic cysteines, $\mathrm{Cys}^{189}$ and $\mathrm{Cys}^{192}$ of mitochondrial Thioredoxin reductase 1 (NTR1, $\left.\Delta \mathrm{OX}_{\mathrm{L}}=65 \%\right)$. Reactive Cys were also found in peroxisomal L-ascorbate peroxidase 3 (APX3, Cys ${ }^{123}, \Delta \mathrm{OX}_{\mathrm{L}}=33 \%$ ), and in GDPmannose 3,5-epimerase $\left(\mathrm{Cys}^{223}, \Delta \mathrm{OX}_{\mathrm{L}}=50 \%, \Delta \mathrm{OX}_{\mathrm{H}}=58 \%\right)$, which is involved in the biosynthesis of L-ascorbate. 


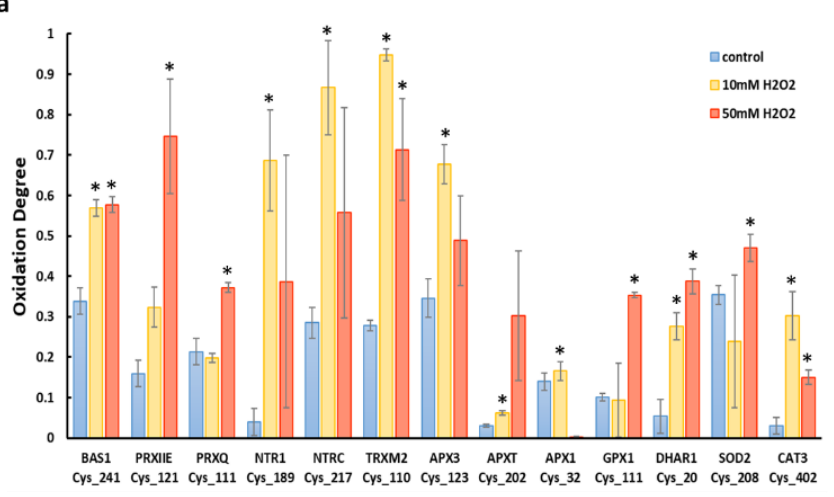

b

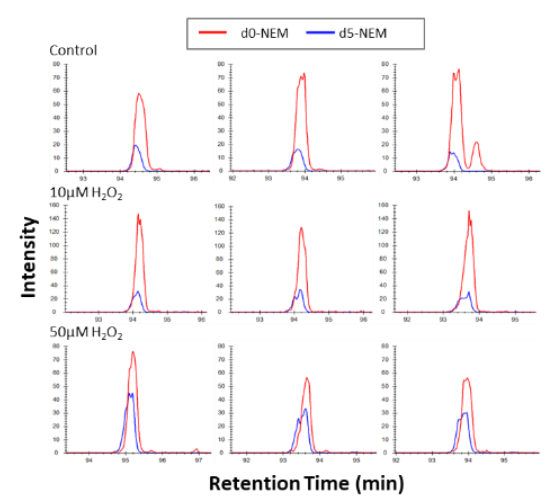

Figure 5. Quantification of cysteine reactivity in redox regulators and antioxidant proteins. (a) The oxidation degree of specific Cys residues in several redox regulators and antioxidant proteins. (b) Skyline display of the ion chromatograms of the PRXQ peptide (GKPVVLYFYPADETPGCTK), which contains the active site Cys ${ }^{111}$. The ion chromatograms of three independent samples for each treatment are presented in each row, under steady-state and following application of $10 \mathrm{mM}$ and $50 \mathrm{mM} \mathrm{H}_{2} \mathrm{O}_{2}$.

We also quantified the response of additional antioxidant proteins, such as catalase-3, $\left(\mathrm{CAT} 3, \mathrm{Cys}^{402}, \Delta \mathrm{OX}_{\mathrm{L}}=27 \%, \Delta \mathrm{OX}_{\mathrm{H}}=12 \%\right) . \mathrm{Cys}^{145}$ and $\mathrm{Cys}^{208}$ in copper$/$ zinc superoxide dismutase 1 and 2 (CSD1/SOD1 and CSD2/SOD2), respectively, were also found to be redox-sensitive $\left(\Delta \mathrm{OX}_{\mathrm{H}}=5 \%\right.$ and $12 \%$, respectively). These two homologous Cys positions form a regulatory intramolecular disulfide (Cys ${ }^{59}$ with $\mathrm{Cys}^{145}$ and $\mathrm{Cys}^{119}$ with $\mathrm{Cys}^{208}$ in SOD1 and SOD2, respectively). Interestingly, these Cys residues, which were found to be regulated by the thioredoxin and glutaredoxin systems, play a role in the stabilization of the structure of SOD1 in human cells (Cys ${ }^{57}$ with $\mathrm{Cys}^{146}$ in hSOD1) and in preventing its aggregation (Álvarez-Zaldiernas et al., 2016). Yet, the role of redox regulation of chloroplast-targeted SOD in plants is yet to be explored.

\section{$\underline{\text { Redox sensitivity of proteins involved in chloroplast metabolism }}$}

Many of the identified redox-sensitive proteins were assigned to metabolic pathways, highlighting the role of redox post-translational modification in dictating the fluxes through these pathways. Mapping of these redox sensitive proteins to metabolic networks was made using the AraCyc and chloroKB tools (Mueller et al., 2003; Gloaguen et al., 2017), highlighting their participation in many essential pathways such as antioxidant homeostasis, starch metabolism, glycolysis, tricarboxylic acid cycle, the pentose phosphate pathway and photosynthesis (Fig. 6). For example, the extracted ion chromatograms showing the redox sensitivity of $\mathrm{Cys}^{443}\left(\Delta \mathrm{OX}_{\mathrm{H}}=40 \%\right)$ of chloroplastic glyceraldehyde-3-phosphate dehydrogenase (GAPDH) is presented in Fig. S4. This 
Cys belongs to the C-terminal extension of the GAPB isoform and is involved in Trxdependent regulation of GAPDH activity by forming a disulfide bond with $\mathrm{Cys}^{434}$, resulting in a kinetically inhibited conformation (Fermani et al., 2007). A similar oxidation response $\left(\triangle \mathrm{OX} \mathrm{X}_{\mathrm{H}}=34 \%\right)$ was also found for $\mathrm{Cys}^{434}$, further demonstrating the sensitivity of these regulatory Cys residues to oxidized conditions (Supp. Table 2). We also observed oxidation of $\mathrm{Cys}^{451}$ and $\mathrm{Cys}^{470}\left(\Delta \mathrm{OX} \mathrm{X}_{\mathrm{H}}=19\right.$ and $19 \%$, respectively) in the C-terminal extension of RuBisCO activase (RCA), which mediates light regulation of RuBisCO activity (Zhang et al., 2002; Portis Jr et al., 2007). Moreover, we observed oxidation of $\mathrm{Cys}^{4491459}\left(\Delta \mathrm{OX}_{\mathrm{L}}=15 \%\right)$ in the large subunit of RubisCO, which are assumed to be involved in redox-dependent inactivation of RubisCO and also contribute to conformational changes that may protect other cysteine residues from further oxidation (Moreno et al., 2008)).

In addition, we identified several redox-sensitive sites in proteins involved in the cyclic electron flow $(\mathrm{CEF})$. These included $\mathrm{Cys}^{82}(\triangle \mathrm{OX} \mathrm{L}=11 \%)$ in PGRL1, which together with PGR5 is involved in antimycin A-sensitive CEF. The identified modified site was found to regulate CEF and NPQ induction by mediating the formation of PGRL1 homodimers through interaction with TRX-m (Hertle et al., 2013; Wolf et al., 2020). Redox regulatory sites were also found in several subunits of NADH dehydrogenaselike (NDH)-complex, including the NDH subunits of subcomplex B2 (Cys ${ }^{122}$, $\left.\Delta \mathrm{OX}_{\mathrm{L}}=20 \%\right)$ and of subunit $\mathrm{U}\left(\mathrm{Cys}^{106}, \Delta \mathrm{OX}_{\mathrm{L}}=51 \%\right.$ and $\left.\Delta \mathrm{OX}_{\mathrm{H}}=50 \%\right)$.

Carbonic anhydrase (CA) catalyzes the reversible interconversion of carbon dioxide $\left(\mathrm{CO}_{2}\right)$ and bicarbonate $\left(\mathrm{HCO}_{3}^{-}\right)$and specifically, beta-CAs are highly abundant in plants and diatoms. Reactive Cys residues were identified in Beta carbonic anhydrase 4 (BCA4) $\left(\mathrm{Cys}^{109}, \Delta \mathrm{OX}_{\mathrm{L}}=35 \%\right)$ and Beta carbonic anhydrase 2 (BCA2) $\left(\mathrm{Cys}^{272}\right.$, $\left.\Delta \mathrm{OX}_{\mathrm{H}}=14 \%\right)$. Redox regulation of $\mathrm{CA}$ has been demonstrated in the diatom Phaeodactylum tricornutum (Kikutani et al., 2012); however, the role of CA redox regulation in plants was not explored.

We also quantified the oxidation degree of Cys residues that coordinate PSI iron-sulfur clusters such as $\mathrm{Cys}^{573}$ in photosystem I P700 chlorophyll a apoprotein A1 (psaA), $\mathrm{Cys}^{559}$ in photosystem I P700 chlorophyll a apoprotein A2 (psaB), and Cys ${ }^{48}$ and Cys ${ }^{54}$ in the photosystem I iron-sulfur center (psaC). These Cys undergo only minor oxidation in response to exogenous $\mathrm{H}_{2} \mathrm{O}_{2}$ application. Indeed, $\mathrm{O}^{-2}$ rather than $\mathrm{H}_{2} \mathrm{O}_{2}$ was shown to inactivate PSI iron-sulfur (FeS) clusters, resulting in PSI photoinhibition under stress conditions (Sonoike et al., 1995; Erling Tjus et al., 1998). As PSI photoinhibition results 
from photooxidation-induced damage of the iron-sulfur (Fe-S) clusters, the ability to biochemically quantify the redox-state of Cys involved in the coordination of PSI electron carriers, provides a new approach for estimating the PSI state.

We found many redox-sensitive Cys residues involved in starch metabolism (Fig. 6). This included redox regulatory sites in ADP-glucose pyrophosphorylase large subunit 1 (ADG2) and in plastid-localized $\beta$-amylases (BAM1-3). For example, we detected significant oxidation of $\mathrm{Cys}^{454}$ of BAM1, which was reported to be regulated by TRXs (Valerio et al., 2011). We couldn't detect the redox state of $\mathrm{Cys}^{82}$ of the small subunit of Arabidopsis AGPase (APS1), a known redox-regulated site involved in redox activation of starch biosynthesis in the light and in response to sucrose accumulation (Fu et al., 1998). Interestingly, we detected a reduction of $\mathrm{Cys}^{363}$ of chloroplastic alphaamylase $3\left(\mathrm{AMY} 3, \Delta \mathrm{OX} \mathrm{X}_{\mathrm{L}}=-44 \%\right.$ and $\left.\triangle \mathrm{OX} \mathrm{X}_{\mathrm{H}}=-42 \%\right)$. Notably, a previous investigation of this regulatory site demonstrated that the C363S mutation displayed higher activity, suggesting that reduced Cys at this site is essential for protein function. As reduced AMY3 has been implicated in enzyme activity, our data suggest that starch redox regulation under oxidative stress conditions will induce starch degradation. Since photosynthesis, the process by which plants generate energy-rich organic compounds, may be limited during oxidative stress, inactivation of a starch synthesis enzyme and activation of a starch degradation enzyme can offer alternative energy and carbon sources essential for plant survival. 


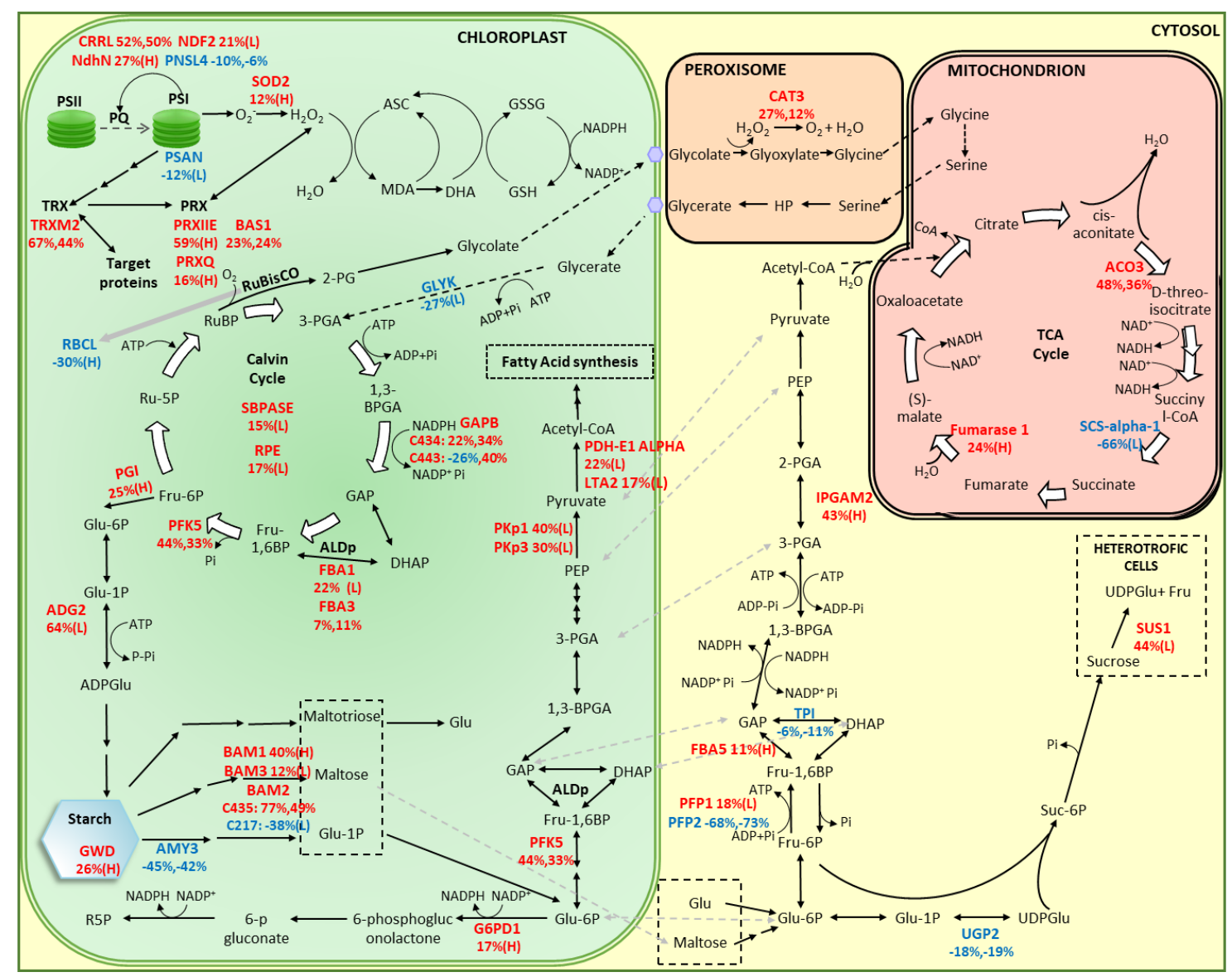

Figure 6: An integrated metabolic map showing redox-sensitive proteins whose oxidative state changed under oxidative stress conditions. Identified redox-sensitive proteins which were oxidized or reduced upon oxidative stress conditions, are shown in red or blue, respectively. Difference in the degree of oxidation ( $\triangle \mathrm{Ox})$ of specific Cys residues in response to $10 \mathrm{mM}$ or $50 \mathrm{mM} \mathrm{H}_{2} \mathrm{O}_{2}$ as indicated by $\mathrm{L}$ (low) and $\mathrm{H}$ (high), respectively. A complete list of abbreviations is provided in Table S5. The metabolic map was adopted from Rosa-Téllez et al. (2018), and changes were included to highlight specific metabolic routes.

\section{Concluding remarks}

The SPEAR workflow provides a global system-level quantitative measurement of the thiol-proteome by deferentially labeling reduced and oxidized thiol groups using light and heavy forms of NEM, without enriching labeled peptides. SPEAR enabled simultaneous retrieval of the precise oxidation degree of thousands of Cys sites and protein abundance information from the same MS run. Thus, SPEAR provides a simple, straightforward, and cost-effective approach for studying redox proteomes dynamics. By applying SPEAR to Arabidopsis leaves exposed to $\mathrm{H}_{2} \mathrm{O}_{2}$, we offer a comprehensive view of Cys reactivity under oxidative stress conditions. Our dataset contained wellknown redox sensors and redox-regulated active sites, which validate the approach, alongside many novel redox-sensitive sites whose roles in plant acclimation to stress conditions remain to be further explored. 


\section{Methods:}

$\underline{\text { Plant growth conditions and treatment }}$

Arabidopsis thaliana ecotype Col-0 plants were grown in a greenhouse under a 16/8 h light/dark cycle. Immunoassay, redox imaging and thiol labeling experiments were performed on 3-week-old whole plants, which were incubated in 40ml DW, 10mM $\mathrm{H}_{2} \mathrm{O}_{2}$ or $50 \mathrm{mM} \mathrm{H}_{2} \mathrm{O}_{2}$ for $20 \mathrm{~min}$ at room temperature. Additionally, for redox imaging, plants were incubated with DTT $(100 \mathrm{mM})$ and $\mathrm{H}_{2} \mathrm{O}_{2}(500 \mathrm{mM})$.

\section{$\underline{\text { Immunoassay }}$}

Protein extract was prepared in $2 \mathrm{ml}$ tubes using a hand homogenizer, in the presence of $1 \mathrm{ml}$ cold $10 \%$ trichloroacetic acid (TCA) dissolved in water. Proteins were precipitated for $30 \mathrm{~min}$ on ice, in the dark, and centrifuged at $14,000 \mathrm{rpm}$, for $20 \mathrm{~min}$, at $4^{\circ} \mathrm{C}$. The pellet was then washed 4 times with $100 \%$ cold acetone. Residual acetone was removed and the pellet was resuspended in urea buffer comprised of $8 \mathrm{M}$ urea, $100 \mathrm{mM} 4-(2-$ hydroxyethyl)-1-piperazineethanesulfonic acid (HEPES) (pH 7.2), 1mM EDTA, 2\% $(\mathrm{w} / \mathrm{v})$ SDS, protease inhibitors cocktail (PI) (Calbiochem) and $100 \mathrm{mM} \mathrm{N}$ ethylmaleimide (NEM) (E3876, Sigma) dissolved in EtOH. The samples were incubated for 30min at room temperature and then centrifuged $(14,000 \mathrm{rpm}, 20 \mathrm{~min}$, $4^{\circ} \mathrm{C}$ ) and washed 4 times with $100 \%$ cold acetone. The dry pellets were resuspended in urea buffer without NEM and then fractionated on a $4-15 \%$ precast polyacrylamide gel without reducing agent. Sample buffer (x3) was comprised of $150 \mathrm{mM}$ Tris-HCl, $\mathrm{pH}$ 6.8, $6 \%(\mathrm{w} / \mathrm{v})$ SDS, $30 \%$ glycerol and $0.3 \%$ pyronin Y. Fractionated proteins were transferred onto polyvinylidene fluoride membrane (Bio-Rad), using a Trans-Blot Turbo Transfer System (Bio-Rad) with Trans-Blot Turbo Midi Transfer Packs. The membrane was incubated with anti-PRX antibodies $(1: 1,000)$ (was kindly provided by Prof. Avichai Danon) or anti-peroxiredoxin-SO3 antibody (ab16830) (1:2000), followed by secondary anti-rabbit horseradish peroxidase (1:20,000) (Agrisera), and later developed using standard protocols.

\section{$\underline{\text { Redox imaging }}$}

Transgenic Arabidopsis lines expressing the roGFP probe in specific organelles, including the cytoplasm (Cy-GRX-roGFP2, Marty et al. 2009), chloroplasts (ChlroGFP2, with transketolase target peptide (Schwarzlander et al. 2008), peroxisomes 
Per-GRX-roGFP2 with peroxisomal targeting signal type 1 SKL amino acid motif, Rosenwasser et al. 2011) and mitochondria (Mit-roGFP2 with the $\beta$ ATPase signal sequence, Rosenwasser et al. 2010) were used to map oxidation in response to various redox conditions. Whole-plant roGFP fluorescence images were taken using an in vivo spectral imager (Ami, Spectral Instruments Imaging), following excitation at 465nm (reduction) and 405nm (oxidation) (emission for both: 510nm). Chlorophyll fluorescence was measured following excitation at 405 (emission: 670nm). RoGFP ratiometric images $(405 / 465)$ were calculated using MATLAB.

\section{Thiol-labeling assay}

Protein extract was prepared in $2 \mathrm{ml}$ tubes using a hand homogenizer, in the presence of $1 \mathrm{ml}$ cold $20 \%$ TCA dissolved in water. Proteins were precipitated for $30 \mathrm{~min}$, on ice, in the dark, and centrifuged at $14,000 \mathrm{rpm}$ for $20 \mathrm{~min}$, at $4^{\circ} \mathrm{C}$. The pellet was washed once with $10 \%$ TCA (dissolved in water) and 2 times with $100 \%$ cold acetone. The residual acetone was removed by brief evaporation and the precipitate was resuspended $(600 \mu \mathrm{l})$ in urea buffer containing 100mM N-ethylmaleimide (d0-NEM) (E3876, Sigma), dissolved in $\mathrm{EtOH}$, to label the reduced cysteines. Samples were incubated at $50^{\circ} \mathrm{C}$ for 30min, with 1000rpm shaking. The reaction was terminated and proteins were precipitated by bringing the TCA content to $20 \%$ (30min, on ice, in the dark), washed once with $10 \%$ TCA and twice with $100 \%$ acetone. Samples were then resuspended in urea buffer supplemented with 5.5mM tris 2-carboxyethyl phosphine (TCEP, Sigma) but without NEM, and shaken (1200rpm, $\left.50^{\circ} \mathrm{C}, 30 \mathrm{~min}\right)$. Samples were further alkylated by adding $5 \mathrm{mM}$ (final concentration) d5-NEM (DLM-6711, CIL) and incubated $\left(50^{\circ} \mathrm{C}\right.$, 30min, 1200rpm shaking). TCA (33\%) was added, samples were precipitated for $30 \mathrm{~min}$, on ice, in the dark and then centrifuged $\left(14,000 \mathrm{~g}, 4^{\circ} \mathrm{C}, 20 \mathrm{~min}\right)$. The pellet was then washed once with 10\% TCA and twice with $100 \%$ acetone. The acetone was removed by $5 \mathrm{~min}$ evaporation and samples were stored at $-80^{\circ} \mathrm{C}$.

An additional set of samples were subjected to thiol labeling as described above, however unlike the former labeling, the reduced cysteines were labeled with $\mathrm{d}_{5}$-NEM. Following precipitation with $20 \%$ TCA, the samples were resuspended $(250 \mu \mathrm{l})$ in urea buffer containing 100mM d5-NEM (dissolved in EtOH), reduced with 5.5Mm TCEP and further alkylated by adding $5 \mathrm{mM}$ (final concentration) dONEM. The samples were stored at $80^{\circ} \mathrm{C}$. 


\section{Sample preparation for LC-MS/MS analysis}

All chemicals were from Sigma Aldrich, unless otherwise indicated. Alkylated proteins were suspended in lysis buffer (5\% SDS, $50 \mathrm{mM}$ Tris-HCl, pH 7.4). After determination of protein concentration using the BCA assay (Thermo Scientific, USA), $100 \mu \mathrm{g}$ total protein of each sample was loaded onto S-Trap mini-columns (Protifi, USA), according to the manufacturer's instructions [1,2]. In brief, after loading, samples were washed with 90:10\% methanol/50mM ammonium bicarbonate and then digested $\left(1.5 \mathrm{~h}, 47^{\circ} \mathrm{C}\right)$ with trypsin (1:50 trypsin/protein). The digested peptides were eluted using $50 \mathrm{mM}$ ammonium bicarbonate and then incubated with trypsin overnight at $37^{\circ} \mathrm{C}$. Two more elution rounds were performed using $0.2 \%$ formic acid and $0.2 \%$ formic acid in $50 \%$ acetonitrile. The three eluted fractions were pooled and vacuum-centrifuged to dryness. Samples were stored at $-80^{\circ} \mathrm{C}$ until analysis.

\section{Liquid chromatography}

ULC/MS-grade solvents were used for all chromatography steps. Each sample was fractionated offline using high-pH reversed-phase separation, followed by online low$\mathrm{pH}$ reversed-phase separation. Digested protein $(100 \mu \mathrm{g})$ was loaded using highperformance liquid chromatography (Agilent 1260 uHPLC). Mobile phase was: A) $20 \mathrm{mM}$ ammonium formate $\mathrm{pH}$ 10.0, B) acetonitrile. Peptides were separated on an XBridge C18 column (3x100mm, Waters) using the following gradient: 3\% B for 2 min, linear gradient to $40 \%$ B over 50min, 5 min to $95 \%$ B, maintained at $95 \%$ B for 5 min and then back to the initial conditions. Peptides were fractionated into 15 fractions. The following fractions were then pooled: 1 with 8,2 with 9, 3 with 10,4 with 11, 5 with 12, 6 with 13 and 7 with 14-15. Each fraction was dried in a speedvac, then reconstituted in $25 \mu \mathrm{L}$ acetonitrile: water+0.1\% formic acid (97:3). Each pooled fraction was then loaded and analyzed using split-less nano-ultra performance liquid chromatography (10 kpsi nanoAcquity; Waters, Milford, MA, USA). The mobile phase was: A) $\mathrm{H}_{2} \mathrm{O}+0.1 \%$ formic acid and $B$ ) acetonitrile $+0.1 \%$ formic acid. Samples were desalted online using a Symmetry C18 reversed-phase trapping column (180 $\mu \mathrm{m}$ internal diameter, $20 \mathrm{~mm}$ length, $5 \mu \mathrm{m}$ particle size; Waters). The peptides were then separated using a T3 HSS nano-column $(75 \mu \mathrm{m}$ internal diameter, $250 \mathrm{~mm}$ length, $1.8 \mu \mathrm{m}$ particle size; Waters) at $0.35 \mu \mathrm{L} / \mathrm{min}$. Peptides were eluted from the column into the mass spectrometer, using the following gradient: $4 \%$ to $27 \%$ B over $105 \mathrm{~min}, 27 \%$ to $90 \%$ B over 5 min, maintenance at $90 \%$ for 5 min and then back to the initial conditions. 


\section{Mass spectrometry}

The nanoUPLC was coupled online through a nanoESI emitter $(10 \mu \mathrm{m}$ tip; New Objective; Woburn, MA, USA) to a quadrupole orbitrap mass spectrometer (Orbitrap Fusion Lumos, Thermo Scientific) using a FlexIon nanospray apparatus (Proxeon). Data were acquired in DDA mode, using a 3-second cycle method. MS1 was performed in the Orbitrap with resolution set to 120,000 (at 200m/z) and maximum injection time set to 50msec. MS2 was performed in the Orbitrap after HCD fragmentation, with resolution set to 15,000 and maximum injection time set to $100 \mathrm{msec}$.

\section{$\underline{\text { Data analysis - protein expression }}$}

Raw data were analyzed using MaxQuant V1.6.0.16.[3]. MS/MS spectra were searched against the Arabidopsis thaliana protein database downloaded from UniProt (www.Uniprot.org). Enzyme specificity was set to trypsin and up to two missed cleavages were allowed. Variable modifications were set to oxidation of methionines, and light (d0) or heavy (d5) NEM labeling of cysteines (+125.0477 or $+130.0791 \mathrm{Da}$, respectively). Peptide precursor ions with a maximum mass deviation of $4.5 \mathrm{ppm}$ and fragment ions with a maximum mass deviation of $20 \mathrm{ppm}$ were searched. Peptide, protein and site identifications were filtered at an FDR of 1\%, using the decoy database strategy. The minimal peptide length was 7 amino acids and the minimum Andromeda score for modified peptides was 40. Peptide identifications were propagated across samples using the match-between-runs option. Searches were performed with the labelfree quantification option selected. Fold changes were calculated based on the ratio of geometric means of the case versus control samples. A Student's t-test, after logarithmic transformation, was used to identify significant differences across the biological replica.

\section{Data analysis - Cys oxidation}

Peptide identification and quantification were conducted using the MetaMorpheus software (v0.0.297 https://smith-chem-wisc.github.io/MetaMorpheus/ or https://github.com/smith-chem-wisc/MetaMorpheus). RAW MS files were searched against the Arabidopsis thaliana (Mouse-ear cress) proteome downloaded from UniProt (UniProtKb Proteome ID UP000006548, as of December 14, 2000, in XML format). All MS files, including the sample in which reduced thiols were labeled with d0-NEM and those labeled with d5-NEM, were jointly processed. In short, the MetaMorpheus calibration task and the G-PTM-D task were performed using the 
default parameters, with the following modifications: nethylmaleimide on $\mathrm{C}$ and $\mathrm{Nem}: 2 \mathrm{H}(5)$ on $\mathrm{C}$ were set as G-PTM-D modifications. The following options were checked in the search settings: apply protein parsimony and construct protein groups, treat modified peptides as different peptides, match between runs, normalize quantification results. An additional MetaMorpheus run was conducted without the GPTM-D algorithm, using Nethylmaleimide on $\mathrm{C}$ and Nem:2H(5) on $\mathrm{C}$ as variable modifications in the search task. Detailed MetaMorpheus parameters used for both runs are provided in Table $\mathrm{S} 4$.

The generated output files AllQuantifiedPeptides.tsv were used for further analysis. First, files were trimmed, and only cysteine-containing peptides labeled with d0 or d5NEM (belongs to the core set in which reduced Cys was labeled with d0-NEM) were selected. Next, a list with peptides bearing both labels was extracted (pairs). A CysID was then assigned to each cysteine-containing peptide; the ID included the UniProt identifier name of the protein and the NEM-labeled cysteine residue position in the protein sequence. Next, the intensity of each peptide throughout the six fractions was summed. If a specific Cys was represented by more than one peptide, the overall intensity of peptides with identical CysIDs was examined and the peptide with the highest intensity was selected for further analysis. The oxidation degree (OxD) of a Cys was calculated using the following formula: $O x D=\frac{d 5}{d 5+d 0}$, where d5 represents the intensity of the d5-NEM labeled peptide and d0 the intensity of the d0-NEM labeled peptide. Only peptides identified in at least two out of three biological replicates were included. Delta oxidation ( $\Delta \mathrm{Ox}$ ) was calculated by subtracting the $\mathrm{OxD}$ of $\mathrm{H}_{2} \mathrm{O}_{2}$-treated plants from the OxD of control plants. The p-value for each peptide was determined using student's t-test.

The OxD for peptides with 2 Cys was calculated twice using the formulas: $O x D=\frac{2 d 5}{2 d 5+2 d 0+d 0 \& d 5}$ or $O x D=\frac{2 d 5+d 0 \& d 5}{2 d 5+2 d 0+d 0 \& d 5}$, where $2 \mathrm{~d} 5$ represents the intensity of the peptide with 2 Cys that both Cys were d5-NEM labeled, $2 \mathrm{~d} 0$ the intensity of the peptide with 2 Cys that both Cys were d0-NEM labeled, and d0\&d5 the intensity of the peptide with 2 Cys that one Cys was d0-NEM labeled and the other Cys was d5-NEM labeled. The two corresponding $\Delta \mathrm{Ox}$ values were calculated and the $\mathrm{p}$-value for each peptide was determined using student's t-test, accordingly. 
Only peptides which passed the threshold of $\Delta \mathrm{Ox}>| \pm 10 \%|$ and $\alpha<0.05$ (at least in one of the applied $\mathrm{H}_{2} \mathrm{O}_{2}$ concentrations) were considered "redox-sensitive peptides". Some of the "redox-sensitive peptides" were imported into Skyline (Pino et al., 2020; an opensource program, can be downloaded at http://proteome.gs.washington.edu/software/skyline) for visualization of the d0- and d5-NEM peak pairs.

\section{$\underline{\text { Functional annotation analysis }}$}

The DAVID (Database for Annotation, Visualization and Integrated Discovery) Bioinformatics Resources tool v6.7was used for mapping protein into Gene Ontology terms (GO) and KEGG (Kyoto Encyclopedia of Genes and Genomes) pathways and for enrichment analysis. Further mapping into metabolic pathways was carried out using the Arabidopsis chloroplast knowledge base (cloroKB, Gloaguen et al., 2017), the AraCyc database from the Plant Metabolic Network (PMN, Mueller et al., 2003), and manual annotation. Subcellular protein localization was predicted using the SUBA tool (the central resource for Arabidopsis protein subcellular location data). Organellespecific enrichment for the proteins whose redox state had changed was calculated based on the cumulative distribution function (CDF) of the hypergeometric distribution (https://systems.crump.ucla.edu/hypergeometric/). $\Delta \mathrm{Ox}$ of Cys belonging to various subcellular compartments was presented using the PlotsOfData tool (https://huygens.science.uva.nl/PlotsOfData/). The Probability logo generator for biological sequence motifs (Plogo, https://plogo.uconn.edu/) was used to estimate the probability of the occurrence of specific amino acid sequence motifs around the NEM labeled Cys. The functional annotation regarding the active and binding sites, metal binding and disulfide bonds, for all the quantified cysteines was retrieved from the UniProt Knowledgebase (https://www.uniprot.org/uploadlists/). The enrichment probability for the "redox-sensitive cysteines" compared to all the quantified cysteines was calculated based on the cumulative distribution function (CDF) of the hypergeometric distribution (https://systems.crump.ucla.edu/hypergeometric/). 


\section{Author contributions:}

S.D., N.L., A.S., Y.L., and S.R. conceived and designed the research. N.L. and A.S., performed the research. S.D., A.S., Y.L and S.R. analyzed the data. S.D. and S.R. wrote the manuscript with inputs from N.L., A.S., and Y.L.

\section{Funding information}

This research was supported by the Israel Science Foundation (grant No. 826/17 and No. 827/17) to SR.

Acknowledgments: We thank Dana Reichmann for her critical comments on the manuscript.

\section{Supplemental data}

The following is the Supplementary data to this article:

Figure S1: RT difference between peptides labeled with d0-NEM and d5-NEM.

Figure S2: Consensus motif of identified Cys containing peptides not labeled with NEM.

Figure S3: Skyline display of the ion chromatograms of the BAS1 peptide (TLQALQYIQENPDEVCPAGWKPGEK).

Figure S4: Skyline display of the ion chromatograms of the GAPB peptide (TNPADEECKVYD).

Figure S5: Violin plot visualization of the difference in the thiol-oxidized state between steady state and exposure to $\mathrm{H}_{2} \mathrm{O}_{2}$ treatment in different subcellular compartments.

Table S1: A list of 17 significantly redox-sensitive peptides derived from using the regular d0NEM and d5-NEM labeling of reduced and oxidized Cys thiols, respectively.

Table S2: A list of 577 significantly redox-sensitive peptides derived from the combined approach including the regular d0-NEM and d5-NEM labeling and oppositely labeled "marker" samples.

Table S3: Changes in proteins expression levels under oxidative stress conditions compared to control. 
Table S4: MetaMorpheus setting parameters used for the two runs, with and without the GPTM-D task, referred to as "method 1" and "method 2", respectively.

Table S5: The pathways abbreviations for the integrated metabolic map presented in Fig. 6.

\section{References:}

Akter S, Huang J, Bodra N, De Smet B, Wahni K, Rombaut D, Pauwels J, Gevaert K, Carroll K, Van Breusegem F, et al (2015) DYn-2 Based Identification of Arabidopsis Sulfenomes. Mol Cell Proteomics 14: 1183-1200

Álvarez-Zaldiernas C, Lu J, Zheng Y, Yang H, Blasi J, Solsona C, Holmgren A (2016) Cellular Redox Systems Impact the Aggregation of Cu,Zn Superoxide Dismutase Linked to Familial Amyotrophic Lateral Sclerosis. J Biol Chem 291: 17197-17208

Anjo SI, Melo MN, Loureiro LR, Sabala L, Castanheira P, Grãos M, Manadas B (2019) oxSWATH: An integrative method for a comprehensive redox-centered analysis combined with a generic differential proteomics screening. Redox Biol 22: 101130

Balmant KM, Parker J, Yoo M-J, Zhu N, Dufresne C, Chen S (2015) Redox proteomics of tomato in response to Pseudomonas syringae infection. Hortic Res 2: 15043

Balmer Y, Vensel WH, Tanaka CK, Hurkman WJ, Gelhaye E, Rouhier N, Jacquot J-P, Manieri W, Schürmann P, Droux M, et al (2004) Thioredoxin links redox to the regulation of fundamental processes of plant mitochondria. Proc Natl Acad Sci U S A 101: 2642 LP - 2647

Brandes N, Reichmann D, Tienson H, Leichert LI, Jakob U (2011) Using quantitative redox proteomics to dissect the yeast redoxome. J Biol Chem 286: 41893-903

Buchanan BB (2016) The Path to Thioredoxin and Redox Regulation in Chloroplasts. Annu Rev Plant Biol 67: 1-24

Buchanan BB, Balmer Y (2005) REDOX REGULATION: A Broadening Horizon. Annu Rev Plant Biol 56: 187-220

Calabrese G, Peker E, Amponsah PS, Hoehne MN, Riemer T, Mai M, Bienert GP, Deponte M, Morgan B, Riemer J (2019) Hyperoxidation of mitochondrial peroxiredoxin limits $\mathrm{H}(2) \mathrm{O}(2)$-induced cell death in yeast. EMBO J 38: e101552-e101552

Consortium U (2019) UniProt: a worldwide hub of protein knowledge. Nucleic Acids Res 47: D506-D515

D'Autréaux B, Toledano MB (2007) ROS as signalling molecules: mechanisms that generate specificity in ROS homeostasis. Nat Rev Mol Cell Biol 8: 813-824

Day AM, Brown JD, Taylor SR, Rand JD, Morgan B a, Veal E a (2012) Inactivation of a peroxiredoxin by hydrogen peroxide is critical for thioredoxinmediated repair of oxidized proteins and cell survival. Mol Cell 45: 398-408

Dietz K-J, Pfannschmidt T (2011) Novel Regulators in Photosynthetic Redox Control of Plant Metabolism and Gene Expression. Plant Physiol 155: 1477 LP 1485

Erling Tjus S, Lindberg Møller B, Vibe Scheller H (1998) Photosystem I Is an Early Target of Photoinhibition in Barley Illuminated at Chilling Temperatures. 
Plant Physiol 116: 755 LP - 764

Fermani S, Sparla F, Falini G, Martelli PL, Casadio R, Pupillo P, Ripamonti A,

Trost $\mathbf{P}$ (2007) Molecular mechanism of thioredoxin regulation in

photosynthetic A2B2-glyceraldehyde-3-phosphate dehydrogenase. Proc Natl

Acad Sci U S A 104: 11109-11114

Foyer CH, Noctor G (2005) Redox homeostasis and antioxidant signaling: a metabolic interface between stress perception and physiological responses. Plant Cell 17: 1866-75

Fristedt R, Williams-Carrier R, Merchant SS, Barkan A (2014) A thylakoid membrane protein harboring a DnaJ-type zinc finger domain is required for photosystem I accumulation in plants. J Biol Chem 289: 30657-30667

Fu L, Liu K, Sun M, Tian C, Sun R, Morales Betanzos C, Tallman KA, Porter NA, Yang Y, Guo D, et al (2017) Systematic and Quantitative Assessment of Hydrogen Peroxide Reactivity With Cysteines Across Human Proteomes. Mol \&amp;amp; Cell Proteomics 16: 1815 LP - 1828

Fu Y, Ballicora MA, Leykam JF, Preiss J (1998) Mechanism of Reductive Activation of Potato Tuber ADP-glucose Pyrophosphorylase *. J Biol Chem 273: 25045-25052

Gadjev I, Vanderauwera S, Gechev TS, Laloi C, Minkov IN, Shulaev V, Apel K, Inzé D, Mittler R, Van Breusegem F (2006) Transcriptomic Footprints Disclose Specificity of Reactive Oxygen Species Signaling in Arabidopsis. Plant Physiol 141: 436 LP - 445

Gerken M, Kakorin S, Chibani K, Dietz K-J (2020) Computational simulation of the reactive oxygen species and redox network in the regulation of chloroplast metabolism. PLOS Comput Biol 16: e1007102

Gloaguen P, Bournais S, Alban C, Ravanel S, Seigneurin-Berny D, Matringe M, Tardif M, Kuntz M, Ferro M, Bruley C, et al (2017) ChloroKB: A Web Application for the Integration of Knowledge Related to Chloroplast Metabolic Network. Plant Physiol 174: 922 LP - 934

Halliwell B (2006) Reactive Species and Antioxidants. Redox Biology Is a Fundamental Theme of Aerobic Life. Plant Physiol 141: 312 LP - 322

Hertle AP, Blunder T, Wunder T, Pesaresi P, Pribil M, Armbruster U, Leister D (2013) PGRL1 Is the Elusive Ferredoxin-Plastoquinone Reductase in Photosynthetic Cyclic Electron Flow. Mol Cell 49: 511-523

Hooper CM, Castleden IR, Tanz SK, Aryamanesh N, Millar AH (2017) SUBA4: the interactive data analysis centre for Arabidopsis subcellular protein locations. Nucleic Acids Res 45: D1064-D1074

Huang J, Willems P, Wei B, Tian C, Ferreira RB, Bodra N, Martínez Gache SA, Wahni K, Liu K, Vertommen D, et al (2019) Mining for protein Ssulfenylation in \&lt;em\&gt;Arabidopsis\&lt;/em\&gt; uncovers redox-sensitive sites. Proc Natl Acad Sci 116: 21256 LP - 21261

Ikegami A, Yoshimura N, Motohashi K, Takahashi S, Romano PGN, Hisabori T, Takamiya K, Masuda T (2007) The CHLI1 Subunit of Arabidopsis thaliana Magnesium Chelatase Is a Target Protein of the Chloroplast Thioredoxin. J Biol Chem 282: 19282-19291

Kikutani S, Tanaka R, Yamazaki Y, Hara S, Hisabori T, Kroth PG, Matsuda Y (2012) Redox Regulation of Carbonic Anhydrases via Thioredoxin in Chloroplast of the Marine Diatom Phaeodactylum tricornutum. J Biol Chem 287: 20689-20700

Laloi C, Apel K, Danon A (2004) Reactive oxygen signalling: the latest news. Curr 
Opin Plant Biol 7: 323-328

Lamkemeyer P, Laxa M, Collin V, Li W, Finkemeier I, Schöttler MA, Holtkamp V, Tognetti VB, Issakidis-Bourguet E, Kandlbinder A, et al (2006)

Peroxiredoxin Q of Arabidopsis thaliana is attached to the thylakoids and functions in context of photosynthesis $\dagger$. Plant J 45: 968-981

Leichert LI, Gehrke F, Gudiseva H V, Blackwell T, Ilbert M, Walker AK, Strahler JR, Andrews PC, Jakob U (2008) Quantifying changes in the thiol redox proteome upon oxidative stress in vivo. Proc Natl Acad Sci U S A 105: 8197-202

Lennicke C, Rahn J, Heimer N, Lichtenfels R, Wessjohann LA, Seliger B (2016) Redox proteomics: Methods for the identification and enrichment of redoxmodified proteins and their applications. Proteomics 16: 197-213

Liu P, Zhang H, Wang H, Xia Y (2014) Identification of redox-sensitive cysteines in the Arabidopsis proteome using OxiTRAQ, a quantitative redox proteomics method. Proteomics 14: 750-762

McDonagh B, Sakellariou GK, Smith NT, Brownridge P, Jackson MJ (2014) Differential cysteine labeling and global label-free proteomics reveals an altered metabolic state in skeletal muscle aging. J Proteome Res 13: 5008-5021

Mock H-P, Dietz K-J (2016) Redox proteomics for the assessment of redox-related posttranslational regulation in plants. Biochim Biophys Acta - Proteins Proteomics 1864: 967-973

Moreno J, García-Murria MJ, Marín-Navarro J (2008) Redox modulation of Rubisco conformation and activity through its cysteine residues. J Exp Bot 59: $1605-1614$

Mueller LA, Zhang P, Rhee SY (2003) AraCyc: A Biochemical Pathway Database for Arabidopsis. Plant Physiol 132: 453 LP - 460

Muthuramalingam M, Matros A, Scheibe R, Mock H-P, Dietz K-J (2013) The hydrogen peroxide-sensitive proteome of the chloroplast in vitro and in vivo. Front Plant Sci 4: 54

Nietzel T, Mostertz J, Ruberti C, Née G, Fuchs P, Wagner S, Moseler A, MüllerSchüssele SJ, Benamar A, Poschet G, et al (2020) Redox-mediated kick-start of mitochondrial energy metabolism drives resource-efficient seed germination. Proc Natl Acad Sci 117: 741 LP - 751

Parker J, Balmant K, Zhu F, Zhu N, Chen S (2015) cysTMTRAQ-An integrative method for unbiased thiol-based redox proteomics. Mol Cell Proteomics 14: 237-242

Petrov VD, Van Breusegem F (2012) Hydrogen peroxide-a central hub for information flow in plant cells. AoB Plants 2012: pls014-pls014

Pino, L K, Searle BC, Bollinger JG, Nunn B, MacLean B, MacCoss, MJ (2020). The Skyline ecosystem: Informatics for quantitative mass spectrometry proteomics. Mass spectrometry reviews, 39(3): 229-244.

Portillo-Ledesma S, Randall LM, Parsonage D, Dalla Rizza J, Karplus PA, Poole LB, Denicola A, Ferrer-Sueta G (2018) Differential Kinetics of Two-Cysteine Peroxiredoxin Disulfide Formation Reveal a Novel Model for Peroxide Sensing. Biochemistry 57: 3416-3424

Portis Jr AR, Li C, Wang D, Salvucci ME (2007) Regulation of Rubisco activase and its interaction with Rubisco. J Exp Bot 59: 1597-1604

Romero-Puertas MC, Laxa M, Mattè A, Zaninotto F, Finkemeier I, Jones AME, Perazzolli M, Vandelle E, Dietz K-J, Delledonne M (2007) S-Nitrosylation of Peroxiredoxin II E Promotes Peroxynitrite-Mediated Tyrosine Nitration. Plant 
Cell 19: 4120 LP - 4130

Rosenwasser S, Fluhr R, Joshi JR, Leviatan N, Sela N, Hetzroni A, Friedman H (2013) ROSMETER: A Bioinformatic Tool for the Identification of

Transcriptomic Imprints Related to Reactive Oxygen Species Type and Origin

Provides New Insights into Stress Responses. Plant Physiol 163: 1071 LP - 1083

Rosenwasser S, Graff van Creveld S, Schatz D, Malitsky S, Tzfadia O, Aharoni

A, Levin Y, Gabashvili A, Feldmesser E, Vardi A (2014) Mapping the diatom redox-sensitive proteome provides insight into response to nitrogen stress in the marine environment. Proc Natl Acad Sci 111: 2740 LP - 2745

Rouhier N, Jacquot J-P (2005) The plant multigenic family of thiol peroxidases. Free Radic Biol Med 38: 1413-1421

Rouhier N, Villarejo A, Srivastava M, Gelhaye E, Keech O, Droux M, Finkemeier I, Samuelsson G, Dietz KJ, Jacquot J-P, et al (2005)

Identification of Plant Glutaredoxin Targets. Antioxid Redox Signal 7: 919-929

Scheibe R, Dietz KJ (2012) Reduction-oxidation network for flexible adjustment of cellular metabolism in photoautotrophic cells. Plant, Cell Environ 35: 202-216

De Smet B, Willems P, Fernandez-Fernandez AD, Alseekh S, Fernie AR, Messens J, Van Breusegem F (2019) In vivo detection of protein cysteine sulfenylation in plastids. Plant J 97: 765-778

Solntsev SK, Shortreed MR, Frey BL, Smith LM (2018) Enhanced Global Posttranslational Modification Discovery with MetaMorpheus. J Proteome Res 17: $1844-1851$

Sonoike K, Terashima I, Iwaki M, Itoh S (1995) Destruction of photosystem I ironsulfur centers in leaves of Cucumis sativus L. by weak illumination at chilling temperatures. FEBS Lett 362: 235-238

Suzuki N, Koussevitzky S, Mittler R, Miller G (2012) ROS and redox signalling in the response of plants to abiotic stress. Plant Cell Environ 35: 259-270

Topf U, Suppanz I, Samluk L, Wrobel L, Böser A, Sakowska P, Knapp B, Pietrzyk MK, Chacinska A, Warscheid B (2018) Quantitative proteomics identifies redox switches for global translation modulation by mitochondrially produced reactive oxygen species. Nat Commun 9: 324

Valerio C, Costa A, Marri L, Issakidis-Bourguet E, Pupillo P, Trost P, Sparla F (2011) Thioredoxin-regulated beta-amylase (BAM1) triggers diurnal starch degradation in guard cells, and in mesophyll cells under osmotic stress. J Exp Bot 62: 545-555

Veal EA, Underwood ZE, Tomalin LE, Morgan BA, Pillay CS (2017) Hyperoxidation of Peroxiredoxins: Gain or Loss of Function? Antioxid Redox Signal 28: $574-590$

Wang H, Wang S, Lu Y, Alvarez S, Hicks LM, Ge X, Xia Y (2012) Proteomic Analysis of Early-Responsive Redox-Sensitive Proteins in Arabidopsis. J Proteome Res 11: 412-424

Waszczak C, Akter S, Eeckhout D, Persiau G, Wahni K, Bodra N, Van Molle I, De Smet B, Vertommen D, Gevaert K, et al (2014) Sulfenome mining in Arabidopsis thaliana. Proc Natl Acad Sci U S A 111: 11545-11550

Waszczak C, Akter S, Jacques S, Huang J, Messens J, Van Breusegem F (2015) Oxidative post-translational modifications of cysteine residues in plant signal transduction. J Exp Bot 66: 2923-2934

Wenderoth I, Scheibe R, von Schaewen A (1997) Identification of the Cysteine Residues Involved in Redox Modification of Plant Plastidic Glucose-6-phosphate Dehydrogenase. J Biol Chem 272: 26985-26990 
Willems P, Mhamdi A, Stael S, Storme V, Kerchev P, Noctor G, Gevaert K, Van Breusegem F (2016) The ROS Wheel: Refining ROS Transcriptional Footprints. Plant Physiol 171: 1720 LP - 1733

Winterbourn CC, Hampton MB (2008) Thiol chemistry and specificity in redox signaling. Free Radic Biol Med 45: 549-561

Woehle C, Dagan T, Landan G, Vardi A, Rosenwasser S (2017) Expansion of the redox-sensitive proteome coincides with the plastid endosymbiosis. Nat plants $\mathbf{3}$ : 17066

Wolf B-C, Isaacson T, Tiwari V, Dangoor I, Mufkadi S, Danon A (2020) Redox regulation of PGRL1 at the onset of low light intensity. Plant J 103: 715-725

Xiao H, Jedrychowski MP, Schweppe DK, Huttlin EL, Yu Q, Heppner DE, Li J, Long J, Mills EL, Szpyt J, et al (2020) A Quantitative Tissue-Specific Landscape of Protein Redox Regulation during Aging. Cell 180: 968-983.e24

Yang J, Carroll KS, Liebler DC (2016) The Expanding Landscape of the Thiol Redox Proteome. Mol Cell Proteomics 15: 1-11

Yin Z, Balmant K, Geng S, Zhu N, Zhang T, Dufresne C, Dai S, Chen S (2017) Bicarbonate Induced Redox Proteome Changes in Arabidopsis Suspension Cells. Front Plant Sci 8: 58

Yoshida K, Noguchi K, Motohashi K, Hisabori T (2013) Systematic exploration of thioredoxin target proteins in plant mitochondria. Plant Cell Physiol 54: 875-892

Yu J, Li Y, Qin Z, Guo S, Li Y, Miao Y, Song C, Chen S, Dai S (2020) Plant Chloroplast Stress Response: Insights from Thiol Redox Proteomics. Antioxid Redox Signal 33: 35-57

Zhang N, Kallis RP, Ewy RG, Portis Jr AR (2002) Light modulation of Rubisco in Arabidopsis requires a capacity for redox regulation of the larger Rubisco activase isoform. Proc Natl Acad Sci U S A 99: 3330-3334 